\author{
Maestría en Economía \\ Facultad de Ciencias Económicas \\ Universidad Nacional de La Plata
}

TESIS DE MAESTRIA

\author{
ALUMNO \\ Joaquín Serrano \\ TITULO \\ Ciclo Económico y Desaceleración de la Participación Lab oral Femenina \\ en América Latina \\ DIRECTOR \\ Mariana Marchionni y Leonardo Gasparini (codirector) \\ FECHA DE DEFENSA \\ 9/23/2016
}




\title{
Ciclo Económico y Desaceleración de la Participación Laboral Femenina en América Latina*
}

\author{
Joaquín Serrano $^{* *}$ \\ Directora: Mariana Marchionni \\ Co-director: Leonardo Gasparini
}

\begin{abstract}
Resumen
El objetivo principal del trabajo es analizar el rol del crecimiento económico en la desaceleración de la PLF que se dio en América Latina a inicios de la década del dos mil. Para ello, se evalúa la relación entre el ciclo económico y la PLF mediante estimaciones de modelos econométricos con efectos fijos, usando datos para 18 países en el período 19872014. Se encuentra que la PLF sigue un patrón contracíclico, especialmente para las mujeres más vulnerables, lo que puede ser explicado por el efecto de trabajador adicional. Asimismo, se aporta evidencia de que la cobertura de programas de transferencias condicionadas es otro factor relevante asociado a la desaceleración de la PLF.
\end{abstract}

Código JEL: J22, J16, N3

Palabras clave: ciclo económico, participación laboral femenina, América Latina

\begin{abstract}
The paper analyzes the role of economic growth in female LFP deceleration that occurred in Latin America since the 2000s. Thus, we asses the relationship between business cycle and female LFP estimating econometric models with fixed effects, using data of 18 countries during 1987-2014. We found that the female LFP follows a countercyclical pattern, especially for vulnerable women, which may be explained by the additional worker effect (AWE). Furthermore, we provide evidence that the coverage of CCTs is another important factor associated with the deceleration of the female LFP.
\end{abstract}

JEL classification: J22, J16, N3

Key words: economic cycle, female labor force participation, Latin America

\footnotetext{
* El presente trabajo constituye la tesis de Maestría en Economía de la UNLP, realizada bajo la dirección de Mariana Marchionni y Leonardo Gasparini. A ellos agradezco su valiosa guía y apoyo a lo largo de todo el proceso de investigación. El trabajo se ha beneficiado de los comentarios y sugerencias de Pablo Glüzmann, Leopoldo Tornarolli, Javier Alejo, Cecilia Parada, Santiago Garganta, María Isabel Egas Salgado y los participantes del seminario de tesis de la Maestría en Economía de la UNLP, a quienes también agradezco. Los eventuales errores son de mi exclusiva responsabilidad.

** Centro de Estudios Distributivos Laborales y Sociales (CEDLAS), Universidad Nacional de La Plata - Consejo Nacional de Investigaciones Científicas y Técnicas (CONICET). E-mail: jserrano@cedlas.org
} 


\section{Introducción}

En las últimas décadas se ha registrado un importante aumento de la participación laboral femenina (PLF) en todo el mundo. En particular, en América Latina durante la segunda mitad del siglo XX se han incorporado al mercado de trabajo alrededor de 70 millones de mujeres, reflejo del importante cambio que ha tenido el rol de las mujeres en la región Chioda 2011. Sin embargo, desde comienzos de la década del 2000 el crecimiento de la participación laboral femenina se ha desacelerado significativamente en la mayoría de los países latinoamericanos e incluso en algunos ha llegado a detenerse, alcanzando una meseta. Este cambio ha sucedido a pesar de un gran aumento del nivel educativo de las mujeres, superando al de los varones, y una caída en los niveles de fecundidad, dos fenómenos que deberían favorecer el aumento de la tasa de actividad laboral femenina Gasparini y Marchionni, 2015a Beccaria et al. 2015.

Esta marcada transformación de la participación laboral de las mujeres puede estar asociada negativamente al empoderamiento femenino en la sociedad World Bank, 2012. Las consecuencias pueden ir más allá de ajustes en el comportamiento de los hogares, alcanzando diversas brechas de género en el mercado laboral, la demanda por políticas de cuidado e, incluso, podría comprometer objetivos de reducción de la pobreza y la desigualdad de ingresos en la región Gasparini y Marchionni, 2015b. Además, podría significar un estancamiento de la oferta global de trabajo, dada la estabilidad de la participación laboral masculina (Beccaria et al. 2015).

Gasparini y Marchionni 2015a sostienen que uno de los factores más importantes detrás de dicha desaceleración es la expansión económica que América Latina ha experimentado en la década de los 2000. Las mejores condiciones macroeconómicas pueden afectar la entrada de las mujeres al mercado laboral al menos de dos formas distintas, con efectos en direcciones opuestas. Por un lado, el mejor contexto económico puede alentar a las mujeres a entrar al mercado de trabajo, viéndose atraídas por mejores condiciones laborales y mayores salarios (efecto sustitución). Por otro lado, el crecimiento económico permite el aumento de los ingresos de los hogares y la consolidación de redes de protección social, factores que alivian la presión de las mujeres a buscar empleo y que afectan negativamente su participación laboral (efecto ingreso). Como las mujeres pertenecientes a hogares más vulnerables tienen una oferta laboral más elástica y sensible frente a cambios en los ingresos, laborales y no laborales, y dado que es este grupo el que experimentó una mayor desaceleración del crecimiento de la participación laboral, se espera que el segundo efecto predomine sobre el primero.

Dada esta situación, este trabajo se propone profundizar las razones que pueden estar detrás de la reciente reducción de la tasa de crecimiento de la participación laboral de las mujeres en América Latina. En particular, el objetivo y contribución del trabajo es estudiar el rol que tiene el fuerte crecimiento económico experimentado por la región desde 
principios de la década del 2000 en la desaceleración de la PLF, evaluando su dinámica a lo largo del ciclo económico. También, analiza si esta relación puede ser explicada por el denominado efecto de trabajador adicional. Además, evalúa la importancia de otro factor potencialmente vinculado a los cambios en la PLF, como es la expansión de la cobertura de programas de transferencias de ingreso condicionadas. Asimismo, se presenta evidencia actualizada de la evolución de la tasa de actividad femenina en América Latina que confirma su estancamiento generalizado, utilizando microdatos de un gran conjunto de encuestas de hogares, que son armonizadas previamente para aumentar la comparabilidad de los resultados entre países.

Como resultado más importante se encuentra que la PLF tiene una dinámica contracíclica: fuertes expansiones del PBI en el corto plazo están asociadas a una reducción de la tasa de actividad laboral de las mujeres. La evidencia es consistente con el efecto de trabajador adicional a la inversa, por el cual mejores condiciones económicas de los trabajadores primarios provocan que trabajadores secundarios posterguen su entrada al mercado laboral. Esta relación es más fuerte para mujeres que tienden a ser trabajadoras secundarias dentro del hogar: con baja educación, casadas, en hogares nucleares de bajos ingresos y en áreas rurales. Por otro lado, el componente tendencial del PBI —asociado a cambios a largo plazo - está relacionado con un aumento de la PLF. Se encuentra una relación asimétrica de la relación del ciclo, según si éste se encuentra por debajo o por encima de la tendencia. Específicamente, se observa que la desaceleración de la PLF en los 2000 está vinculada a expansiones de corto plazo en la fase positiva del ciclo económico.

Adicionalmente, se aporta evidencia de que los programas de transferencias de ingresos condicionadas constituyen otro factor relevante asociado a la desaceleración de la actividad laboral femenina. En particular, se encuentra que ante un aumento en la cobertura de dichas transferencias, la PLF se reduce. Este resultado es consistente con la hipótesis de que las mujeres deciden retrasar su entrada al mercado laboral debido a mayores ingresos no laborales y al tiempo que consume cumplir con las condicionalidades asociadas al subsidio.

El trabajo se organiza de la siguiente manera. En la sección 2 se realiza una breve revisión de la literatura empírica previa sobre determinantes de la participación laboral femenina en América Latina. En la sección 3 se detallan la fuentes de datos que se utilizan a lo largo del trabajo. Luego, en la sección 4, se analiza la relación entre el ciclo económico y la desaceleración de la participación laboral femenina en la región. Para ello se describen los hechos estilizados y las hipótesis a estudiar, se explica la estrategia empírica y se presentan los resultados. Finalmente, la sección 5 concluye el trabajo con algunos comentarios finales. 


\section{Antecedentes}

La reducción de la tasa de crecimiento de la participación laboral femenina en América Latina es un hecho relativamente reciente, por lo que hay poca evidencia empírica que de cuenta de dicha transformación. Gasparini y Marchionni 2015a documentan extensivamente la evolución de la participación de las mujeres en el mercado laboral para los países de América Latina desde inicios de la década de los 90, constatando su reciente desaceleración. Asimismo analizan los factores que están asociados al comportamiento de la misma y de las políticas públicas que la afectan 1

La participación laboral femenina está vinculada a muchos elementos. Busso y Fonseca 2015 y Chioda 2011 presentan un marco conceptual según el cual los factores que explican el comportamiento de la PLF se pueden clasificar en aquellos que dependen de decisiones y/o preferencias de los individuos y en factores que se encuentran fuera del control de los mismos. Dentro del primer grupo se pueden encontrar las decisiones vinculadas a la inversión en capital humano (educación) y a la formación de la familia (matrimonio, fecundidad, etc.). Dentro del segundo grupo se encuentran los retornos del mercado laboral (salarios full-time y part-time, brechas salariales de género, etc.), tecnología del hogar (artefactos del hogar, electricidad, internet) y de la salud (métodos anticonceptivos), factores culturales (religión católica, discriminación de género) y las políticas públicas (impuestos, transferencias de ingreso condicionadas, servicios de cuidado, licencias de maternidad). Las variables que más nos interesan en este trabajo son las relacionadas a las condiciones macroeconómicas que forman parte del segundo grupo de factores, e incluyen el crecimiento del producto y los ciclos económicos, con sus respectivas crisis y recesiones. Todos estos factores a su vez están relacionados entre sí y un análisis apropiado debería tener en cuenta este hecho.

Busso y Fonseca 2015 realizan un meta-análisis sobre los determinantes de la PLF y estiman modelos bivariados con efectos fijos por país para analizar la importancia relativa de cada factor para explicar la evolución de la PLF en América Latina. Sus resultados sugieren que la tendencia creciente a largo plazo de la misma ha sido impulsada principalmente por la expansión de las tecnologías de la salud y del hogar y por cambios culturales que se han desarrollado paulatinamente durante un largo período. A su vez, esta tendencia se ha potenciado por factores tradicionales como la mayor educación y la disminución de la fecundidad, cambios que se retroalimentan positivamente con la participación de las mujeres en la fuerza laboral $2^{2}$ Respecto al estancamiento reciente de la PLF, encuentran que probablemente haya sido provocado por las mayores tasas de crecimiento económico experimentado en la región, la fuerte expansión de los programas

1 Beccaria et al. 2015 también presentan evidencia de la desaceleración de la tasa de actividad femenina para el caso de Argentina.

${ }^{2}$ Otros trabajos arriban a conclusiones similares mediante descomposiciones, como Peña et al. 2013. para Colombia o Gasparini et al. 2015 para los países de América Latina. 
de transferencias condicionadas y por la discriminación de género en la región.

Hay trabajos que analizan el rol de las condiciones macroeconómicas a través de la estimación del efecto de recesiones y crisis económicas sobre la PLF. De esta forma, tratan de evaluar la existencia del llamado efecto de trabajador adicional (AWE, por sus siglas en inglés) y si éste prevalece frente al denominado efecto de trabajador desalentado. El concepto fue identificado originalmente por Woytinsky 1940 y luego desarrolado por Ashenfelter 1980, Heckman y Macurdy 1980, Lundberg 1985 y Borjas 2005. Bajo un modelo estático simple, el AWE consiste en que los trabajadores secundarios del hogar, comúnmente esposas mujeres, entran al mercado laboral luego de una reducción transitoria de los ingresos familiares (por ejemplo, porque el sostén del hogar queda desempleado) $\mathrm{3}^{3}$ Entonces, el AWE no es más que un típico efecto ingreso que surge a nivel del hogar en el contexto de un modelo unitario, y que asume que hay mujeres con un rol de trabajadoras secundarias y que el ocio es un bien normal. En un contexto de modelos de ciclo de vida, en la medida de que la pérdida de ingresos por el desempleo sea pequeña en relación a los ingresos del trabajador primario, se espera que el AWE sea pequeño y concentrado en las familias con restricciones de liquidez Lundberg, 1985.

Eventualmente, el AWE puede ser neutralizado por un efecto sustitución, llamado efecto del trabajador desalentado, generado por las malas perspectivas económicas en el mercado de trabajo. Si este último efecto es más que compensado por el AWE, la participación laboral de las mujeres debería tener un comportamiento contracíclico.

En la práctica, estos efectos dependen de varios factores, como la disponibilidad de estrategias alternativas para aliviar el shock negativo de ingresos (trabajo infantil, seguro de desempleo, etc.) y la existencia de mercados imperfectos de crédito y restricciones de liquidez. En consecuencia, estudios empíricos para países desarrollados, como Estados Unidos o el Reino Unido, encuentran un efecto de trabajador adicional pequeño Gruber y Cullen, 1996, Stephens, 2002. En cambio, en economías subdesarrolladas como las latinoamericanas, el efecto puede ser mucho más grande, ya que generalmente carecen de una política de seguro de desempleo extendida, muchos de sus hogares enfrentan restricciones financieras y el rol de trabajadoras secundarias de las mujeres se ve reforzado por sólidas estructuras tradicionales familiares, niveles bajos de educación y de calificación laboral. Además, en estos países el sector informal tiende a ser importante, lo que permite que las mujeres puedan participar del mercado laboral fácilmente, porque las barreras a la entrada y salida son relativamente bajas Basu et al. 2000.

Existen varios estudios empíricos que analizan la validez de la hipótesis de AWE en la región. Por ejemplo, Martinoty 2015 utiliza el colapso de la convertibilidad en Argentina como experimento natural para evaluar el efecto de los cambios en el

\footnotetext{
${ }^{3}$ A su vez, el efecto puede ser potenciado si el aumento del tiempo fuera del mercado laboral de los trabajadores primarios disminuye el costo de oportunidad de realizar actividades de mercado para las mujeres trabajadoras secundarias, a través de la sustitución de las tareas dentro del hogar.
} 
estado laboral de varones casados sobre las decisiones de participación de sus esposas, encontrando que existe un efecto de trabajador adicional estadísticamente significativo. Dicho resultado va en la misma dirección que el encontrado por Cerrutti 2000 para Argentina en la década de los 90, por Paz 2009 para el mismo país en la década siguiente, por Fernandes y Felicio 2005 para Brasil y por Parker y Skoufias 2004 para México. Por otro lado, se encuentran los trabajos de McKenzie 2003a y McKenzie 2003b en donde se analizan las estrategias de los hogares para compensar shocks negativos provenientes de la crisis financiera argentina del 2002 y la del peso mexicano de 1995, respectivamente. En los mismos se sostiene que la entrada al mercado laboral no fue un mecanismo importante para mantener el nivel de bienestar de los hogares, debido a la existencia de una restricción de demanda laboral.

También existen trabajos que utilizan datos agregados para estudiar el comportamiento cíclico de la oferta de trabajo de las mujeres. Con datos macro, a diferencia de lo que ocurre con datos a nivel individual, generalmente tiende a dominar el efecto de trabajador desalentado y la PLF se vuelve procíclica Tachibanaki y Sakura, 1991; Darby et al. . 1998; Lee y Parasni, 2014).4 Sin embargo, los estudios que se enfocan en países subdesarrollados arrojan resultados más variados. Por ejemplo, Cox Edwards y Roberts 1994 analizan países de América Latina entre 1965 y 1987 y encuentran que el AWE es significativo para países de bajos ingresos pero no para países más ricos, como Chile o Argentina. Un caso más reciente es el de Bhalotra y Umana-Aponte 2010, quienes utilizan datos individuales de 63 países en desarrollo, combinándolos con un panel de países con variables agregadas como el PBI, durante el período 1986-2006. Encuentran que para América Latina y Asia la relación entre empleo femenino y crecimiento es en promedio negativa, pero positiva en África. Las autoras sostienen que las características que potencian las respuestas contracíclicas incluyen el bajo nivel educativo, estar casadas con personas de bajo nivel educativo, residencia rural y alta fecundidad, entre otras características vinculadas a la escasez de riqueza. Este trabajo complementa estos resultados y mejora la estrategia empírica, ya que utiliza datos de mayor calidad (más países de América Latina, con series más largas y comparables entre sí) y centra su análisis directamente sobre la participación laboral de las mujeres en vez de usar la tasa de empleo.

En la misma linea se encuentra el trabajo de Gasparini y Gluzmann 2015, quienes analizan la relación entre el crecimiento del PBI y sus componentes cíclico y tendencial con

\footnotetext{
${ }^{4}$ En relación a este tema, existe una variada literatura reciente, teórica y empírica, que trata de reconciliar las diferencias entre estimaciones de elasticidades de la oferta laboral femenina respecto a los salarios, según estén basadas en datos micro o en datos agregados. Por ejemplo, Attanasio et al. 2015 estiman un modelo de ciclo de vida para explicar la oferta laboral femenina de Estados Unidos, tratando de saldar las discrepancias entre estimaciones micro y macro. Entre otros resultados, encuentran que las elasticidades agregadas de la oferta laboral varían a lo largo del ciclo económico, siendo más fuertes durante las recesiones.
} 
la participación de las mujeres en la fuerza laboral. Los autores argumentan que es poco probable que el estancamiento de la PLF sea un fenómeno permanente, especialmente teniendo en cuenta que países en desarrollo similares a los latinoamericanos tienen tasas de actividad laboral femenina más altas y aun crecientes. Por el contrario, sostienen que podría ser un fenómeno transitorio vinculado al gran crecimiento económico que experimentó América Latina a comienzos del 2000. Estas mejores condiciones económicas, que permitieron mejorar la situación laboral del sostén de los hogares, pudieron haber provocado un efecto de trabajador adicional a la inversa, haciendo que las mujeres decidieran postergar su entrada a la fuerza laboral debido a la menor presión por salir a buscar trabajo. También sugieren otros potenciales canales, como la expansión y consolidación de sistemas de protección social, que implicaron transferencias de ingreso no laboral a los hogares y pudieron tener un efecto negativo sobre la PLF. Realizando estimaciones econométricas simples encuentran que la PLF tiene un comportamiento contracíclico y que es más fuerte para las mujeres de nivel educativo bajo.

Este trabajo pretende profundizar el análisis realizado por Gasparini y Gluzmann 2015, superando algunas limitaciones y diferenciándose en varios sentidos. En primer lugar, todos los modelos estimados en dicho estudio son bivariados, es decir, no incluyen controles adicionales que pudieran estar correlacionados con las variables de interés. En cambio, en este trabajo se estiman modelos multivariados, combinando variables vinculadas al contexto macroeconómico (crecimiento y su ciclo) con otras relacionadas a cambios demográficos y de políticas públicas. Para ello se extiende el período bajo análisis (incorporando encuestas posteriores a 2012) y se desagregan las mujeres en grupos según nivel educativo y edad para cada país, incrementando el número de observaciones. Los modelos multivariados permiten estimar con mayor precisión las correlaciones parciales entre la participación laboral y los factores asociados a la misma, controlando además por efectos fijos en el tiempo y por país. En segundo lugar, se propone complementar las variables asociadas a la PLF con mayor información, por ejemplo, incluyendo en los modelos variables que capturen la intensidad de la relación entre la PLF y las transferencias condicionadas de ingresos, utilizando el número de beneficiarios o el tamaño de los programas. Esta información no se encuentra disponible en las encuestas de hogares y requiere el uso de otras fuentes de datos. Esto permite enriquecer el análisis, al controlar por otros factores distintos al ciclo económico, que pueden estar asociados a la disminución del crecimiento de la actividad laboral femenina.

\section{Fuentes de Datos}

La evidencia empírica de este trabajo se basa principalmente en el procesamiento de microdatos de encuestas de hogares, las cuales son parte de la Socioeconomic Database for Latin America and the Caribbean (SEDLAC), un proyecto desarrollado conjuntamente 
por el CEDLAS de la Universidad Nacional de La Plata y el grupo de pobreza para LAC del Banco Mundial (LCSPP). SEDLAC contiene información sobre más de 300 encuestas de hogares de 25 países de América Latina y el Caribe. En este trabajo se utilizarán microdatos de los 17 países de América Latina continental y la República Dominicana 5 El Cuadro B.1 detalla las encuestas utilizadas en este trabajo.

Las encuestas de hogares no son uniformes entre los países latinoamericanos y en varios casos, ni siquiera dentro de un país a lo largo del tiempo. Dado que la cuestión de la comparabilidad es de una gran preocupación, se ha hecho un gran esfuerzo para obtener estadísticas comparables entre países y a través del tiempo mediante el uso de definiciones similares de variables y la aplicación de métodos consistentes de procesamiento de los datos (ver SEDLAC, 2014).

Cuando no hay cambios en las encuestas (por ejemplo, cambios en la cobertura geográfica) y las series estadísticas son comparables en el tiempo, no se efectúa ningún ajuste. Cuando las series no son necesariamente comparables a lo largo del tiempo debido a cambios en la encuesta, existen tres alternativas posibles. En primer lugar, se pueden utilizar las series sin tener en cuenta el problema de la comparabilidad. En segundo lugar, se podría usar sólo los años que sean comparables, utilizando menos datos. Por último, se pueden realizar algunos ajustes para proporcionar una mayor comparabilidad y utilizar todos los años disponibles. En este caso, se elige la tercera alternativa, siempre y cuando se tenga los datos de la encuesta con y sin el cambio específico que afecta la comparabilidad (por ejemplo, antes y después de la ampliación de la cobertura geográfica).6

Cuando en este trabajo se presentan estadísticas descriptivas para el agregado de América Latina, se muestran promedios no ponderados de estadísticas de 15 países pertenecientes a la región円Ponderar por la población implicaría analizar un fenómeno afectado fuertemente por los países más poblados, como Brasil y México, casi ignorando la situación en otras naciones menos pobladas. La presentación de promedios para cada año requiere tener un panel balanceado; es decir, la información sobre una estadística dada para la misma muestra de países en cada año. Dado que varios países de la región no cuentan con encuestas nacionales de hogares cada año, se construye un panel balanceado realizando interpolaciones y extrapolaciones lineales usando información de

\footnotetext{
${ }^{5}$ La mayoría de las encuestas de hogares incluidas en la muestra son representativas a nivel nacional; las excepciones son Uruguay antes de 2006 y Argentina, donde las encuestas cubren sólo la población urbana que sin embargo representa más del $85 \%$ de la población total.

${ }^{6}$ Para realizar el ajuste, primero se calculan las estadísticas utilizando la encuesta con y sin el cambio que afecta la comparabilidad. Luego, se calcula la relación entre los dos indicadores, y seguidamente se ajustan las estadísticas de años anteriores utilizando esta relación.

${ }^{7}$ Se incluyen todos los países de América Latina continental, con la excepción de Colombia y Guatemala. Mientras que el primero tiene un cuerpo coherente y comparable de su Encuesta Nacional de Hogares solamente para la década del 2000, Guatemala todavía no tiene un sistema consolidado de encuestas.
} 
encuestas adyacentes del mismo país. Para los países que no poseen encuestas antes de un cierto año, y con el fin de completar la serie hasta al menos el año 1990, se utiliza una extrapolación constante, extendiendo el dato del primer año disponible hasta 1990. Un procedimiento similar se aplica para completar, de ser necesario, las series hasta el año 2014. Cabe aclarar que para las estimaciones econométricas se usa el panel no balanceado, sin extrapolaciones ni interpolaciones.

El análisis de la oferta de trabajo está restringido a personas de 25 a 54 años de edad. Se opta por centrar el análisis en esta subpoblación para poder evitar incluir factores que están más relacionadas con el empleo de los jóvenes que con el enfoque de género. También, se limita el análisis a las personas menores de 55 años, ya que el empleo en las personas mayores tiene otros determinantes y una dinámica diferente (por ejemplo, es muy relevante el sistema de pensiones).

Las variables que van más allá de las características demográficas, sociales y laborales de las personas, como el PBI per cápita, presencia de leyes, características institucionales o la cobertura de programas sociales, se obtienen de fuentes alternativas (por ejemplo, de la base de datos WEO del FMI, WDI del Banco Mundial o de CEPALSTAT). En el Cuadro B2 se describen las variables usadas a lo largo del trabajo, sus definiciones y sus fuentes de datos.

\section{Ciclo ecónomico y participación laboral femenina}

El principal fenómeno que se destaca en este estudio es la desaceleración de la PLF en América Latina que se evidencia hacia mediados de la década del 2000, luego de un sostenido aumento durante la década anterior $8 \mathrm{El}$ contraste en las tasas de crecimiento de ambos períodos no es representativo de todos los países de América Latina, pero es suficientemente generalizado para ser visible en el promedio de la región: Argentina, Bolivia, Brasil, Chile, Costa Rica, Ecuador, Honduras, Mexico, Panamá, Paraguay, Perú y Venezuela experimentan una desaceleración en el crecimiento de la participación laboral de las mujeres a partir de la década del 2000, en algunos se reduce levemente y en otros incluso se estanca (Figura A1, Apéndice A). También puede observarse que la tasa de actividad laboral de los varones siempre se mantiene alta y más estable a lo largo del tiempo. Dadas estas diferencias entre géneros, la brecha de participación laboral entre varones y mujeres en la región cae alrededor de 10 puntos porcentuales desde

\footnotetext{
${ }^{8}$ La Figura A3 del apéndice A, muestra la evolución de la oferta laboral de las mujeres para América Latina, utilizando diferentes grupos de países para calcular promedios simples según la disponibilidad de encuestas. Se puede observar que independientemente de agregar o no países al cálculo del promedio, la desaceleración es clara. Mientras que la participación laboral femenina aumenta a razón de 0,8 puntos porcentuales por año entre 1990 y 2005, ésta se reduce a 0,3 puntos porcentuales entre 2005 y 2014 . La desaceleración es evidente también dividiendo a los países en subregiones (América del Sur y América Central) como así también comparando economías con niveles iniciales de participación relativamente altos y bajos (figuras no incluidas en el trabajo).
} 
inicios de los 90 hasta mediados de los 2000, y luego continúa cerrándose ligeramente hasta la actualidad.

Esta evidencia confirma que la desaceleración de la PLF mostrada por Gasparini y Marchionni 2015a se extiende incluso hasta el año 2014. Dichos autores encuentran que este patrón es más marcado para las mujeres en condiciones más vulnerables, especialmente aquellas con un nivel educativo bajo, que habitan en áreas rurales, casadas y que tienen hijos. Se espera que estas mujeres tengan a su vez una oferta laboral más elástica y que entren o salgan del mercado laboral dependiendo de la situación económica dentro y fuera de sus hogares. El hecho de que la desaceleración durante la década de los 2000 sea especialmente fuerte entre estos grupos de mujeres, sugiere que los cambios en el contexto socioeconómico pueden estar jugado un rol importante en la explicación de los cambios de la PLF.

En América Latina, el producto bruto interno promedio crece a una tasa anual de $1,9 \%$ entre 1990 y 1999, para luego aumentar a una tasa del 2,5\% entre el 2000 y el 2014, incluso considerando los años marcados por crisis severas con un gran impacto negativo sobre las tasas de crecimiento $9 \mathrm{El}$ crecimiento promedio es incluso mayor si se toma el período entre 2005 y 2014 excluyendo el año 2009, y casi duplica la tasa de la década del 90 (3,7\%). Más allá del mayor crecimiento, la década del 2000 se caracteriza por tener una mayor estabilidad macroeconómica, a diferencia de las décadas anteriores.

En la Figura 1 se puede apreciar que el fuerte aumento del PBI per cápita en la región coincide con la desaceleración de la participación laboral femenina Io Si bien la mejora en el contexto macroeconómico puede fomentar el aumento de la PLF a través del efecto sustitución, también puede afectarla de forma negativa a través de un aumento de los ingresos familiares, haciendo que las mujeres puedan decidir postergar su entrada al mercado laboral ante una menor necesidad de buscar empleo fuera del hogar.

Este argumento es una variante de la hipótesis del efecto del trabajador adicional (AWE, por sus siglas en inglés), al que generalmente se recurre para poder explicar el aumento de la PLF para hacer frente a schoks de desempleo y de reducción de ingresos familiares durante recesiones económicas. En forma análoga, durante un período de fuerte expansión económica, a medida que mejoran las condiciones laborales de los trabajadores primarios y el hogar recupera sus ingresos reales, las mujeres pueden verse desalentadas a participar del mercado de trabajo. Los incentivos sobre las mujeres no necesariamente implican una salida del mercado laboral, sino sólo una postergación de

\footnotetext{
${ }^{9}$ Las crisis que afectaron globalmente a la región en este período fueron las crisis financieras con epicentro en el Sudeste de Asia (1997), Este de Asia (1997) y Rusia (1998). Algunos países tuvieron crisis específicas, como México (1994-1995), Brasil (1998-1999), Argentina (2001), Uruguay (2002) y la República Dominicana (2003). En 2008 se dio una nueva crisis financiera global que afectó negativamente a más de la mitad de los países de la región.

${ }^{10}$ La Figura A2 (Apéndice A) muestra las series del PBI per cápita para cada país analizado en el trabajo.
} 
Figura 1. Participación laboral femenina y crecimiento económico.

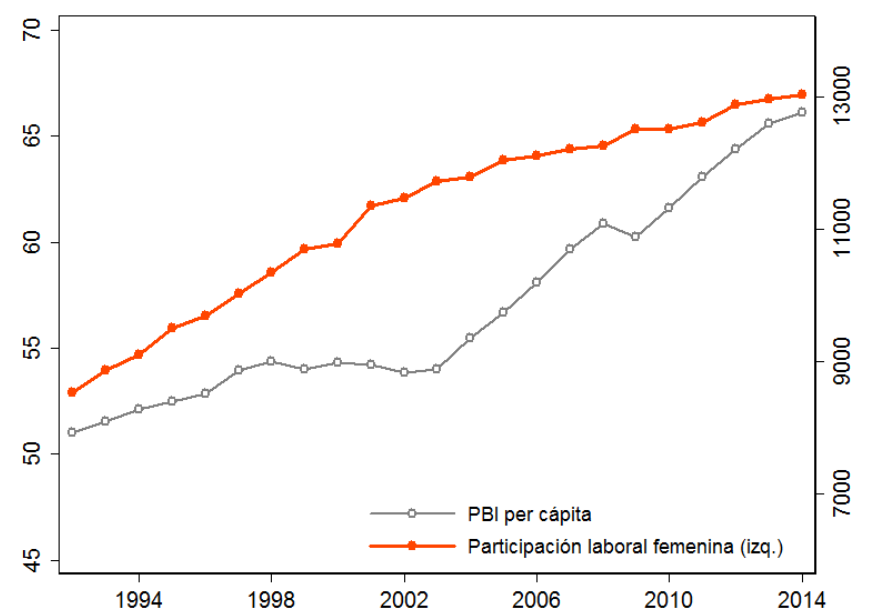

Fuente: Elaboración propia en base a microdatos provenientes de encuestas de hogares. PBI per cápita (en U\$D constantes 2005) de WDI. Nota: Mujeres entre 25 y 54 años. Promedios no ponderados de países de América Latina.

la decisión de entrar al mismo, por ejemplo, para dedicar más tiempo al cuidado de sus hijos o de adultos mayores. Alternativamente, las mejores condiciones económicas dentro y fuera del hogar pueden aliviar la presión de las mujeres a aceptar cualquier tipo de trabajo, y, en cambio, pueden tener la posibilidad de esperar hasta que encuentren alguno que se corresponda con sus preferencias.

Si esta hipótesis es válida, la PLF debería tener un comportamiento contracíclico, esto es, un movimiento en dirección opuesta al ciclo económico. Desde luego, para que surja este patrón, el efecto ingreso debe más que compensar el efecto sustitución. En este sentido, es importante notar que el AWE es mucho más relevante para las mujeres que viven en hogares relativamente más vulnerables. Las mujeres pobres, con un nivel educativo bajo y con hijos, tienen una mayor probabilidad de actuar como trabajadoras secundarias, teniendo una relación mucho más débil con el mercado laboral y, por lo tanto, sus decisiones laborales son más sensibles a las condiciones económicas. Además, estas mujeres son aquellas cuyos hogares más se benefician de la mejora de la situación económica en los 2000, a través de un aumento del empleo y de las remuneraciones de los varones.

Para entender estas relaciones, la Figura 2 muestra la evolución de algunas variables laborales para varones de entre 25 y 54 años, que, dado el fenómeno del matching, son aquellos que tienen mayor probabilidad de ser los esposos de las mujeres de ese mismo rango de edades. Primero, se puede observar que la brecha en el ingreso laboral horario entre varones con alto y bajo nivel educativo se reduce sustancialmente durante la década del 2000. Este hecho no solo sugiere que los ingresos familiares se incrementan para las mujeres en hogares más vulnerables, sino que dicho aumento es relativamente más alto respecto al experimentado por hogares no pobres. Este patrón es acompañado 
por una marcada caída en el desempleo de los varones con baja calificación, que cae desde un 6,1 \% en 2002 hasta un 3,7\% en 2014, en contraste con un comportamiento más estable del desempleo para los más calificados, que fluctúa entorno al 4\%. De este modo, la Figura 2 sugiere la existencia de un efecto de trabajador adicional potencialmente relevante, en particular entre las mujeres más vulnerables, en la medida que su decisión de participar del mercado de trabajo dependa de la situación laboral de otros miembros del hogar, especialmente esposos.

Figura 2. Brechas entre varones con alto y bajo nivel educativo.

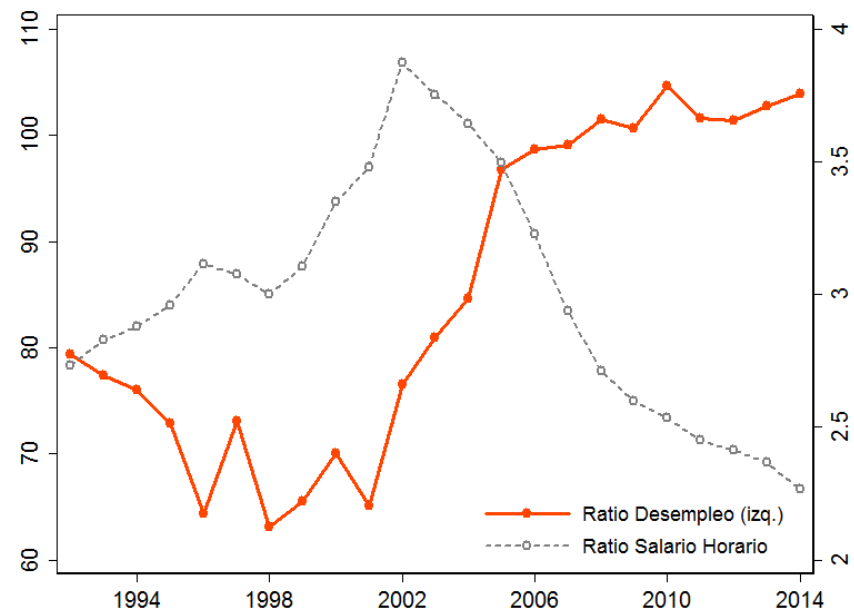

Fuente: Elaboración propia en base a microdatos provenientes de encuestas de hogares. PBI per cápita (en U \$D constantes 2005) de WDI. Nota: Varones entre 25 y 54 años. Promedios no ponderados de países de América Latina.

Un factor adicional que podría explicar la desaceleración de la PLF es el efecto ingreso vinculado a mayores transferencias del Estado, especialmente los programas de transferencias de ingresos condicionadas (CCT, por su sigla en inglés), que a partir de los 2000 aumentan en cantidad y en intensidad en América Latina, como muestra la Figura 3a. Los CCTs consisten en transferencias, generalmente monetarias, a hogares de recursos escasos con niños, condicionales a que el hogar cumpla con inversiones en el capital humano de los niños (educación, salud y alimentación). Actualmente, prácticamente todos los países de América Latina cuentan con alguna forma de programas de transferencias condicionadas, llegando a alcanzar a gran parte de la población pobre - según Stampini y Tornarolli 2012 la cobertura en México, Brasil y Colombia llega alrededor del 50 \% y en Uruguay asciende incluso al $80 \%$

Los incentivos económicos introducidos por los CCTs podrían ser ambiguos respecto a los cambios en la PLF. Por un lado, pueden tener un efecto negativo, a través de tres vias. En primer lugar, pueden inducir un efecto ingreso, por el cual mayores

\footnotetext{
${ }^{11}$ Los CCTs no son el único instrumento de política dirigido al alivio de la pobreza. Las pensiones no contributivas, por ejemplo, se han expandido fuertemente en la región durante los 2000, sumando otra fuente más de ingresos no laborales para los hogares más vulnerables.
} 
transferencias estatales pueden significar un alivio para las mujeres en la presión por buscar trabajo, demorando la decisión de participar del mercado laboral. En segundo lugar, dado que generalmente las mujeres son las perceptoras de las transferencias y, por ello, el cumplimiento de las condicionalidades recae principalmente sobre ellas, su tiempo disponible para trabajar en actividades de mercado puede verse reducido, lo que a su vez puede reforzar los roles de género tradicionales dentro del hogar Garganta et al. 2015. En tercer lugar, los beneficiarios de los CCTs pueden creer que para seguir siendo elegibles para el programa tienen que trabajar menos para seguir siendo pobres. Por otro lado, los CCTs pueden tener efectos positivos sobre la PLF. Si las condicionalidades requieren que los hijos vayan a la escuela, podrían implicar que las mujeres puedan asignar más tiempo a actividades de mercado al dejar de destinarlo al cuidado de los niños. Además, esto podría conllevar que los niños tengan menos tiempo para trabajar, lo que disminuiría el ingreso del hogar y aumentaría la demanda de ingresos laborales dentro de la familia Busso y Fonseca, 2015).

La Figura 3b presenta la evolución de la actividad laboral de las mujeres según pertenecen a hogares que reciben transferencias del estado o no (éstas incluyen transferencias condicionadas y otras pensiones no contributivas, sean monetarias o no, excluyendo jubilaciones). Se puede observar que las tasas de participación laboral son prácticamente iguales durante la década de los 90, mientras que a partir del 2000 se abre una brecha debido a una caída en la participación laboral de las mujeres cuyos hogares reciben transferencias (5,7 puntos porcentuales de diferencia en 2014), hecho consistente con la hipótesis del efecto ingreso negativo. En la práctica, según el meta-análisis realizado por Busso y Fonseca 2015, los CCTs tienen generalmente un efecto negativo sobre la PLF y sobre las horas trabajadas, aunque varios trabajos para países de la región encuentran un efecto estadísticamente no significativo.

Dada la evidencia anterior, puede decirse que la expansión económica que experimenta América Latina durante los 2000 tiene un efecto más intenso sobre los ingresos de los hogares más vulnerables, que, además, son aquellos en donde las mujeres son más propensas a cambiar sus decisiones de participación laboral basadas en las perspectivas económicas del hogar. En consecuencia, según este argumento se debería observar una fuerte desaceleración en la participación laboral de las mujeres casadas, poco calificadas, y más vulnerables, hipótesis consistente con la evidencia presentada por Gasparini y Marchionni 2015a.

Como se ha argumentado en esta sección, hay varias razones para explicar la desaceleración de la PLF, especialmente la vinculada al ciclo económico. Sin embargo, es claro que la evidencia presentada hasta ahora es descriptiva y está lejos de ser concluyente. Esta relación podría ser económicamente irrelevante o estadísticamente no significativa, al ser compensada por factores no incluidos en el análisis, que operan en otras direcciones. En consecuencia, el rol del efecto del ciclo sobre la PLF se analizará a 
Figura 3. Transferencias del Estado en América Latina

(a) Cobertura de CCTs (\%)

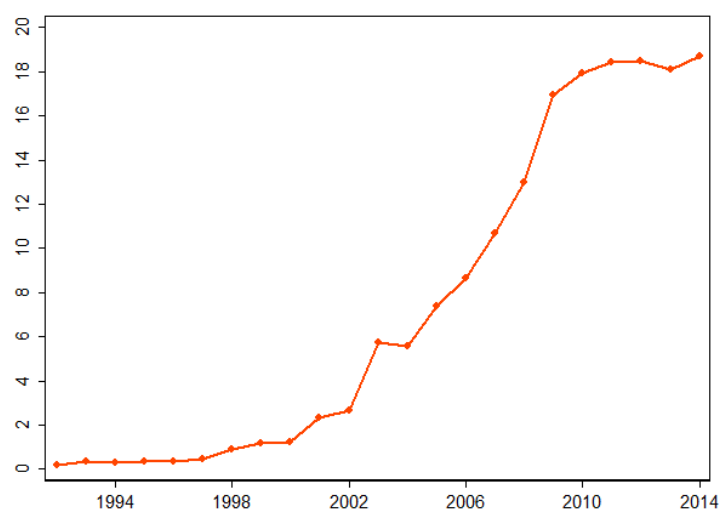

(b) Participación laboral femenina y transferencias del Estado.

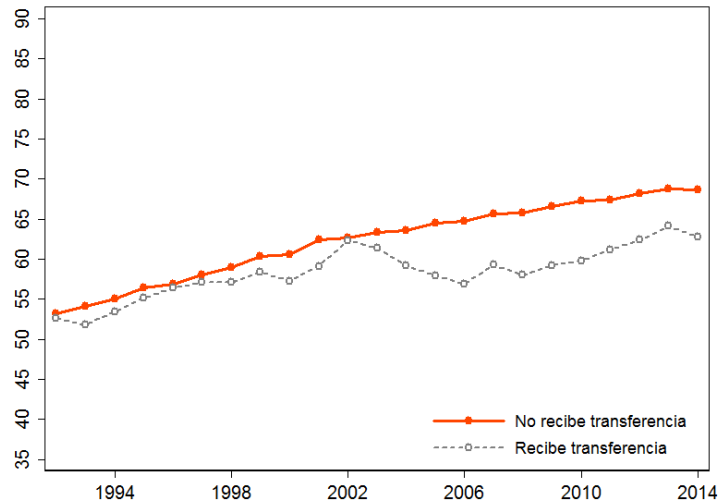

Fuente: Elaboración propia en base a (a) datos de Cepal y a (b) microdatos provenientes de encuestas de hogares. Nota: En figura (b), corresponde a mujeres entre 25 y 54 años, promedios no ponderados, recibe (no recibe) transferencia= hogar que recibe transferencias, monetarias y/o no monetarias, del Estado.

través de estimaciones econométricas, cuyos resultados se presentan en las siguientes secciones.

\subsection{Estrategia empírica}

Para analizar la dinámica de la participación laboral femenina a lo largo del ciclo económico se propone utilizar un marco de estimaciones econométricas con datos en panel, pudiendo controlar por heterogeneidad entre países no observada fija en el tiempo y por factores que se espera estén asociados a la variable de interés. Para ello se construye un panel de 18 países de América Latina en el período 1987-2014 y se estiman modelos con efectos fijos de la participación laboral de las mujeres y otras variables laborales:

$$
\begin{aligned}
& Y_{c t}=\alpha+\beta \ln (\text { PBIpc })_{c t}+\eta_{c}+\epsilon_{t}+\mu_{c t} \\
& Y_{c t}=\alpha+\beta_{1} \text { ciclo }_{c t}+\beta_{2} \text { tendencia }{ }_{c t}+\eta_{c}+\epsilon_{t}+\mu_{c t}
\end{aligned}
$$

en donde la variable explicada $Y_{c t}$ es la tasa de participación laboral agregada u otras variables del mercado laboral (como la tasa de ocupación, de desocupación, salarios, brechas) para el país $c$ en el momento $t$, y como variables explicativas se incluye el logaritmo del PBI per cápita (en dólares ajustados por PPA), y alternativamente sus componentes cíclico y tendencial, estimados a partir del filtro de Hodrick-Prescott 12 Los efectos fijos para los países, $\eta_{c}$, absorben las características que varían entre países pero son fijas en el tiempo, ya sean observables o no, evitando posibles fuentes de sesgo por variables omitidas. Algunas especificaciones incluyen efectos fijos por año, $\epsilon_{t}$, que

\footnotetext{
${ }^{12}$ Se usa un parámetro de suavización $\lambda=100$. Ver Hodrick y Prescott 1997.
} 
neutralizan aún más las tendencias comunes para toda la región y por lo tanto ayudan a que las relaciones de interés se identifiquen a partir de efectos idiosincráticos de cada país 13

Con el objetivo de analizar la importancia del efecto de trabajador adicional, se estiman modelos similares al (2), pero incluyendo como variable explicativa adicional la tasa de desempleo masculina, $u_{n} h_{g c t}$. De este modo, si la hipótesis del efecto de trabajador adicional a la inversa es válida, se espera que al incorporar este factor la significatividad estadística del coeficiente estimado del componente cíclico del PBI per cápita se reduzca. Además, para evaluar la relación entre las transferencias condicionadas de ingresos y los cambios en la PLF, se introduce una variable de cobertura de dichos programas, $c_{c t}$. Para aumentar el número de observaciones, se propone desagregar la unidad de panel, utilizando grupos de mujeres conformados según edad y nivel educativo, pudiendo construir modelos anidados dentro de un panel de países no balanceado $4 \mathrm{El}$ modelo básico incluye efectos fijos por grupo:

$$
\begin{aligned}
& Y_{g c t}=\alpha+\beta_{1} \text { cicloct }_{c}+\beta_{2} \text { tendencia }_{c t}+\beta_{3} \text { unh }_{g c t}+\beta_{4} c c t_{c t}+\eta_{g c}+\epsilon_{t}+\mu_{g c t} \\
& Y_{g c t}=\alpha+\beta_{1} \text { ciclo }_{c t}+\beta_{2} \text { tendencia }_{c t}+\beta_{3} \text { unh }_{g c t}+\beta_{4} c c t_{c t}+\phi X_{c t}+\theta Q_{g c t}+\eta_{g c}+\epsilon_{t}+\mu_{g c t}
\end{aligned}
$$

en donde $X_{c t}$ son controles que varian entre países y a través del tiempo, y $Q_{g c t}$ son variables explicativas que también varían entre grupos, como las planteadas en el marco conceptual mencionado anteriormente en los antecedentes. Tanto el aumento de las observaciones como la inclusión de estos controles contribuyen a mejorar la precisión de los estimadores. Sin embargo, en la medida que estén altamente correlacionadas con el PBI, su ciclo o tendencia, se estará bajo presencia de alta multicolinealidad, lo que podría evitar que se pueda observar la correlación entre el ciclo y la participación laboral.

En todos los casos se puede estimar las ecuaciones para las mujeres, los varones, y la brecha de género, y así poder identificar diferencias en la relación con el ciclo. Asimismo, se pueden obtener resultados para diferentes grupos de mujeres (por ejemplo, según nivel educativo, estado civil, área de residencia, número de hijos), permitiendo evaluar heterogeneidades en los efectos estimados y así comprender mejor qué tipo de mujeres son las más afectadas por el ciclo.

Como un ejercicio adicional, se plantea una estrategia de identificación del efecto causal del componente cíclico del PBI sobre la PLF. En las estimaciones anteriores el problema de la endogeneidad se aborda controlando por distintos factores relevantes, incluida la heterogeneidad no observada que varía entre países pero que es constante en

\footnotetext{
${ }^{13}$ En la práctica, los efectos fijos por año pueden introducirse por separado para cada país para controlar por tendencias específicas para cada uno de ellos. Dado que la variable independiente de interés utilizada - el PBI - varía por país y por año, esta especificación no es posible. Un enfoque alternativo para capturar tendencias específicas es incluir una tendencia en el tiempo para subgrupos de países.

${ }^{14}$ En total se constituyen 9 grupos, resultantes de la cruza de tres grupos de nivel educativo (bajo, medio y alto) y tres grupos de edad (25-34, 35-44, 45-54).
} 
el tiempo. Sin embargo, esta estrategia puede resultar insuficiente, porque no soluciona otras fuentes de endogeneidad, como los errores de medición de las variables explicativas o la causalidad inversa entre el ciclo económico y la PLF.

Se propone, entonces, generar un shock exógeno sobre el componente cíclico utilizando como potenciales instrumentos válidos algunas variables meteorológicas, como niveles de temperatura y precipitaciones anuales promedio Brückner y Ciccone 2011, Miguel et al. 2004, quienes usan esta última variable para instrumentar el PBI). Bhalotra y Umana-Aponte 2010 también implementan esta estrategia y encuentran que los instrumentos son fuertes, aunque con sus datos, no superan test de sobreidentificación. La validez de los instrumentos se discuten en la siguiente sección. Para la estimación se utiliza el método de mínimos cuadrados en dos etapas, considerando alternativamente al componente cíclico y tendencial como variables endógenas.

\subsection{Resultados}

En esta sección se analiza la dinámica de la participación laboral femenina a lo largo del ciclo económico utilizando estimaciones de modelos econométricos. El Cuadro 1 presenta los principales resultados del trabajo, mostrando estimaciones de modelos con efectos fijos de la participación laboral femenina en base a un panel no balanceado de 18 países de América Latina en el período 1987-2014. Como variables explicativas se incluyen alternativamente el logaritmo del PBI per cápita (en dólares ajustados por PPA) obtenido del WEO del FMI, como así también sus componentes cíclico y tendencial. Se observa que los cambios en el PBI están estrecha y positivamente relacionados con la participación laboral femenina: un aumento del 10\% del PBI per cápita se asocia a un aumento en la participación laboral femenina de aproximadamente 1,42 puntos porcentuales, en promedio.

$\mathrm{Al}$ descomponer el producto, se encuentra una relación estadísticamente significativa tanto con el componente cíclico como con el tendencial, aunque con signos opuestos. Por un lado, el componente tendencial está asociado a un aumento en la participación laboral femenina (1,49 pp.). Por el otro, la oferta laboral de las mujeres parece tener una dinámica contracíclica frente a los movimientos de corto plazo de la economía: un aumento del $10 \%$ en el componente cíclico del producto se traduce en una reducción en la participación laboral femenina de aproximadamente 1,68 puntos porcentuales. Este resultado es coherente con la hipótesis de que el reciente estancamiento es fomentado por el crecimiento experimentado por la mayoría de los países de la región durante los 200015

\footnotetext{
${ }^{15}$ Según el Cuadro B3 (Apéndice B), la tasa de ocupación también está relacionada positivamente al crecimiento del PBI, tanto para varones como para mujeres. El efecto del componente tendencial es positivo y particularmente fuerte para las mujeres, mientras que el ciclo lo es especialmente para los varones. Además, el desempleo está negativamente relacionado con el PBI, y los efectos tanto del
} 
Si se comparan los resultados anteriores con los correspondientes a los varones se puede observar que los cambios en el producto, como en su componente cíclico y tendencial, no están asociados a su oferta de trabajo. Como consecuencia, la brecha de participación laboral entre varones y mujeres tiene una relación negativa con la tendencia del PBI per cápita, pero positiva con el componente cíclico. En otras palabras, a lo largo del proceso de desarrollo económico, la participación laboral femenina ha aumentado, reduciendo la brecha de género de forma tendencial. Sin embargo, las expansiones de corto plazo del PBI están asociadas a una disminución de la entrada de las mujeres al mercado laboral, y en consecuencia, a una ampliación de la brecha de género.

El resultado de la dinámica contracíclica de la actividad laboral femenina es similar al hallado en Gasparini y Marchionni 2015a para América Latina y en Bhalotra y Umana-Aponte 2010 para la misma región y países en desarrollo de Asia. En dichos trabajos, no sólo el signo es el mismo, sino que las magnitudes de las relaciones son también similares.

Cuadro 1. Modelos de participación laboral ( \%). Países de América Latina, panel 1987-2014. Individuos entre 25-54 años.

\begin{tabular}{|c|c|c|c|c|c|c|}
\hline & \multicolumn{2}{|c|}{ Mujeres } & \multicolumn{2}{|c|}{ Varones } & \multicolumn{2}{|c|}{ Ratio varones/mujeres } \\
\hline & (1) & (2) & $(3)$ & (4) & $(5)$ & $(6)$ \\
\hline Log PBI per cápita & $\begin{array}{c}14.2^{* * *} \\
(10.16)\end{array}$ & & $\begin{array}{c}-0.8 \\
(-1.62)\end{array}$ & & $\begin{array}{c}-46.3^{* * *} \\
(-5.95)\end{array}$ & \\
\hline Componente cíclico & & $\begin{array}{c}-16.8^{* * *} \\
(-3.60)\end{array}$ & & $\begin{array}{c}1.9 \\
(1.24)\end{array}$ & & $\begin{array}{c}48.8^{* * *} \\
(3.94)\end{array}$ \\
\hline Componente tendencial & & $\begin{array}{l}14.9^{* * *} \\
(10.51)\end{array}$ & & $\begin{array}{c}-0.8 \\
(-1.73)\end{array}$ & & $\begin{array}{c}-48.2^{* * *} \\
(-6.15)\end{array}$ \\
\hline Observaciones & 304 & 304 & 304 & 304 & 304 & 304 \\
\hline R-cuadrado & 0.672 & 0.730 & 0.062 & 0.076 & 0.601 & 0.647 \\
\hline
\end{tabular}

Notas: Estimaciones con efectos fijos (por país). Panel no balanceado de 18 países. Participación laboral como porcentaje de adultos (mujeres o varones) entre 25-54 años. Estadísticos t robustos entre paréntesis. ${ }^{*}$ significativo al $10 \%$; ** significativo al $5 \%$; *** significativo al $1 \%$.

\section{Heterogeneidades}

Para explorar posibles heterogeneidades, se construye un índice de vulnerabilidad, a través del método de componentes principales en base al estado civil, el nivel educativo componente cíclico como tendencial son negativos y estadísticamente significativos para ambos géneros. A su vez, los salarios aumentan cuando el PBI se expande para varones y mujeres. Aumentos del PBI tendenciales reducen la brecha salarial de género, mientras que las expansiones de corto plazo la reducen. 
y el número de hijos en el hogar. El Cuadro 2 presenta las estimaciones de los modelos comparando a personas en los quintiles 1 y 5 del índice de vulnerabilidad (vulnerables y no vulnerables, respectivamente) y también dividiendo a las personas según niveles educativos. Según el índice, las mujeres vulnerables son aquellas con muy bajo nivel educativo, mayormente casadas que habitan en áreas rurales, con una alta cantidad de hijos menores de edad, con bajos ingresos. ${ }^{16}$

La relación negativa del componente cíclico del PBI y la participación laboral es particularmente fuerte y altamente significativa para las mujeres vulnerables y con menos años de educación formal (menos de secundaria completa). Para los varones la relación con el producto sólo es estadísticamente significativa para aquellos de nivel educativo bajo, aunque la magnitud parece ser relativamente pequeña. Para ese grupo el componente tendencial está negativamente relacionado a la participación laboral, mientras que el componente cíclico no tiene un efecto significativo. En cuanto a la brecha de participación laboral entre varones y mujeres, el ciclo tiene un efecto positivo y particularmente fuerte sobre el grupo de vulnerables y de menor educación. Lo mismo ocurre con la tendencia pero con el signo contrario.

Estos resultados son consistentes con la hipótesis enunciada anteriormente, en la cual las mujeres menos educadas que viven en hogares más vulnerables tienen una mayor probabilidad de reaccionar frente a las fluctuaciones económicas. Específicamente, en el caso de América Latina, la repentina y fuerte expansión de su economía en los 2000 puede haber cumplido un rol no despreciable en la fuerte desaceleración de la participación laboral de las mujeres más vulnerables.

\section{Efecto de trabajador adicional, CCTs y factores asociados}

Según las hipótesis planteadas en la sección anterior, el comportamiento contracíclico de la PLF se debe fundamentalmente a la existencia del efecto de trabajador adicional. Para poder analizar la presencia de este efecto, incluímos en el modelo la tasa de desempleo de los varones. Se incorpora, alternativamente, una variable que capta la cobertura de las transferencias de ingresos condicionadas, ya que es uno de los factores que también puede estar detrás de la desaceleración reciente de la PLF. Asimismo, se presentan modelos controlando por variables que posiblemente sean determinantes o estén asociados a la PLF: factores que se determinan conjuntamente a las decisiones de oferta laboral (educación, matrimonio, fecundidad) y factores que los individuos no pueden controlar directamente (brecha salarial de género, costo del cuidado de niños y

\footnotetext{
${ }^{16}$ Los Cuadros B4, B5 B6, B7 y B8 (Apéndice B) muestran estimaciones separando a las personas por números de hijos en el hogar, quintiles de ingreso per cápita familiar, estado civil, área de residencia y tipo de familias, respectivamente. Los resultados son consistentes con aquellos expuestos en el Cuadro 2 .
} 
Cuadro 2. Modelos de participación laboral (\%). Países de América Latina, panel 1987-2014. Individuos entre 25-54 años.

A. Mujeres

\begin{tabular}{|c|c|c|c|c|c|c|c|c|c|c|}
\hline & \multicolumn{2}{|c|}{ No vulnerables } & \multicolumn{2}{|c|}{ Vulnerables } & \multicolumn{2}{|c|}{ Nivel educativo bajo } & \multicolumn{2}{|c|}{ Nivel educativo medio } & \multicolumn{2}{|c|}{ Nivel educativo alto } \\
\hline & (1) & $(2)$ & (3) & (4) & (5) & (6) & (7) & (8) & (9) & (10) \\
\hline Log PBI per cápita & $\begin{array}{c}8.8^{* * *} \\
(5.66)\end{array}$ & & $\begin{array}{c}14.7^{* * *} \\
(7.85)\end{array}$ & & $\begin{array}{c}12.1^{* * *} \\
(8.11)\end{array}$ & & $\begin{array}{l}5.3^{* *} \\
(2.77)\end{array}$ & & $\begin{array}{c}5.6^{* * *} \\
(3.75)\end{array}$ & \\
\hline Componente cíclico & & $\begin{array}{c}-6.0 \\
(-1.23)\end{array}$ & & $\begin{array}{c}-20.6^{* * *} \\
(-3.24)\end{array}$ & & $\begin{array}{c}-18.2^{* * *} \\
(-3.12)\end{array}$ & & $\begin{array}{c}-16.6^{* *} \\
(-2.84)\end{array}$ & & $\begin{array}{c}-9.4^{* * *} \\
(-2.97)\end{array}$ \\
\hline Componente tendencial & & $\begin{array}{l}9.1^{* * *} \\
(5.63)\end{array}$ & & $\begin{array}{c}15.5^{* * *} \\
(8.06)\end{array}$ & & $\begin{array}{c}12.7^{* * *} \\
(8.32)\end{array}$ & & $\begin{array}{l}5.8^{* * *} \\
(3.05)\end{array}$ & & $\begin{array}{c}5.9^{* * *} \\
(3.89)\end{array}$ \\
\hline Observaciones & 304 & 304 & 304 & 304 & 304 & 304 & 304 & 304 & 304 & 304 \\
\hline R-cuadrado & 0.417 & 0.439 & 0.510 & 0.563 & 0.547 & 0.609 & 0.183 & 0.239 & 0.261 & 0.295 \\
\hline \multicolumn{11}{|l|}{ B. Varones } \\
\hline & \multicolumn{2}{|c|}{ No vulnerables } & \multicolumn{2}{|c|}{ Vulnerables } & \multicolumn{2}{|c|}{ Nivel educativo bajo } & \multicolumn{2}{|c|}{ Nivel educativo medio } & \multicolumn{2}{|c|}{ Nivel educativo alto } \\
\hline & (1) & $(2)$ & (3) & (4) & (5) & (6) & (7) & (8) & (9) & (10) \\
\hline Log PBI per cápita & $\begin{array}{c}-0.9 \\
(-1.71)\end{array}$ & & $\begin{array}{c}0.4 \\
(0.60)\end{array}$ & & $\begin{array}{l}-1.4^{* *} \\
(-2.38)\end{array}$ & & $\begin{array}{c}-0.1 \\
(-0.17)\end{array}$ & & $\begin{array}{c}0.2 \\
(0.22)\end{array}$ & \\
\hline Componente cíclico & & $\begin{array}{c}4.4 \\
(1.61)\end{array}$ & & $\begin{array}{c}0.3 \\
(0.22)\end{array}$ & & $\begin{array}{c}1.8 \\
(1.27)\end{array}$ & & $\begin{array}{c}1.7 \\
(0.61)\end{array}$ & & $\begin{array}{c}1.5 \\
(1.13)\end{array}$ \\
\hline Componente tendencial & & $\begin{array}{c}-1.0^{*} \\
(-1.84)\end{array}$ & & $\begin{array}{c}0.4 \\
(0.58)\end{array}$ & & $\begin{array}{l}-1.4^{* *} \\
(-2.49)\end{array}$ & & $\begin{array}{c}-0.1 \\
(-0.23)\end{array}$ & & $\begin{array}{c}0.1 \\
(0.18)\end{array}$ \\
\hline Observaciones & 304 & 304 & 304 & 304 & 304 & 304 & 304 & 304 & 304 & 304 \\
\hline R-cuadrado & 0.021 & 0.035 & 0.011 & 0.011 & 0.142 & 0.155 & 0.001 & 0.004 & 0.001 & 0.002 \\
\hline \multicolumn{11}{|c|}{ C. Ratio varones/mujeres } \\
\hline & \multicolumn{2}{|c|}{ No vulnerables } & \multicolumn{2}{|c|}{ Vulnerables } & \multicolumn{2}{|c|}{ Nivel educativo bajo } & \multicolumn{2}{|c|}{ Nivel educativo medio } & \multicolumn{2}{|c|}{ Nivel educativo alto } \\
\hline & (1) & $(2)$ & (3) & (4) & (5) & (6) & (7) & (8) & (9) & (10) \\
\hline Log PBI per cápita & $\begin{array}{c}-14.5^{* * *} \\
(-5.73)\end{array}$ & & $\begin{array}{c}-118.4^{* * *} \\
(-4.28)\end{array}$ & & $\begin{array}{c}-60.1^{* * *} \\
(-5.11)\end{array}$ & & $\begin{array}{c}-12.8^{* *} \\
(-2.67)\end{array}$ & & $\begin{array}{r}-7.7^{* * *} \\
(-4.23)\end{array}$ & \\
\hline Componente cíclico & & $\begin{array}{c}15.2^{* *} \\
(2.63)\end{array}$ & & $\begin{array}{c}102.4^{* *} \\
(2.47)\end{array}$ & & $\begin{array}{c}66.9^{* * *} \\
(3.18)\end{array}$ & & $\begin{array}{c}37.9^{* * *} \\
(4.23)\end{array}$ & & $\begin{array}{c}14.7^{* * *} \\
(3.64)\end{array}$ \\
\hline Componente tendencial & & $\begin{array}{c}-15.1^{* * *} \\
(-5.72)\end{array}$ & & $\begin{array}{c}-122.8^{* * *} \\
(-4.40)\end{array}$ & & $\begin{array}{c}-62.7^{* * *} \\
(-5.22)\end{array}$ & & $\begin{array}{c}-13.9^{* * *} \\
(-2.91)\end{array}$ & & $\begin{array}{c}-8.1^{* * *} \\
(-4.46)\end{array}$ \\
\hline Observaciones & 304 & 304 & 304 & 304 & 304 & 304 & 304 & 304 & 304 & 304 \\
\hline R-cuadrado & 0.379 & 0.408 & 0.459 & 0.488 & 0.528 & 0.571 & 0.219 & 0.282 & 0.295 & 0.340 \\
\hline
\end{tabular}

Notas: Estimaciones con efectos fijos (por país). Panel no balanceado de 18 países. Participación laboral como porcentaje de adultos (mujeres o varones) entre 25-54 años. Estadísticos t robustos entre paréntesis. * significativo al $10 \%$; ** significativo al $5 \%$; *** significativo al $1 \%$. 
ancianos, salarios de las mujeres, valor agregado del sector servicios, población rural) ${ }^{17 \|^{8}}$

Dado que se incorporan muchas variables a los modelos, para aliviar el problema de pocas observaciones se construye otro panel más desagregado, utilizando como unidad de observación grupos de nivel educativo cruzados con grupos de edad para cada país. El Cuadro 3 presenta los resultados principales de las estimaciones de los modelos (3) y (4) sobre la participación laboral femenina, con efectos fijos por país, grupo de edad y nivel educativo. Todas las estimaciones son robustas a la inclusión adicional de efectos fijos por tiempo (cuadros no mostrados) 19

Cuadro 3. Modelos de participación laboral femenina (\%). Países de América Latina, panel de cohortes según educación y edad, 1987-2014. Individuos entre 25-54 años.

\begin{tabular}{|c|c|c|c|c|c|c|c|c|}
\hline & (1) & $(2)$ & $(3)$ & $(4)$ & $(5)$ & (6) & $(7)$ & $(8)$ \\
\hline Componente cíclico & $\begin{array}{c}-14.7^{* * *} \\
(-6.64)\end{array}$ & $\begin{array}{c}-13.8^{* * *} \\
(-5.79)\end{array}$ & $\begin{array}{c}-11.3^{* * *} \\
(-5.02)\end{array}$ & $\begin{array}{c}-8.5^{* * *} \\
(-3.52)\end{array}$ & $\begin{array}{c}-10.6^{* * *} \\
(-4.39)\end{array}$ & $\begin{array}{c}-9.9 * * * \\
(-4.12)\end{array}$ & $\begin{array}{c}-7.8^{* * *} \\
(-3.33)\end{array}$ & $\begin{array}{l}-4.8^{* *} \\
(-2.05)\end{array}$ \\
\hline Componente tendencial & $\begin{array}{l}9.3^{* * *} \\
(12.64)\end{array}$ & $\begin{array}{c}4.7^{* * *} \\
(4.36)\end{array}$ & $\begin{array}{c}10.3^{* * *} \\
(9.55)\end{array}$ & $\begin{array}{l}7.2^{* * *} \\
(6.74)\end{array}$ & $\begin{array}{l}9.2^{* * *} \\
(12.03)\end{array}$ & $\begin{array}{c}5.4^{* * *} \\
(4.98)\end{array}$ & $\begin{array}{c}10.0^{* * *} \\
(9.20)\end{array}$ & $\begin{array}{l}7.6^{* * *} \\
(7.37)\end{array}$ \\
\hline Cobertura CCT & & & $\begin{array}{c}-3.3 \\
(-1.28)\end{array}$ & $\begin{array}{c}-8.0 * * * \\
(-4.14)\end{array}$ & & & $\begin{array}{c}-2.8 \\
(-1.13)\end{array}$ & $\begin{array}{r}-7.9^{* * *} \\
(-4.07)\end{array}$ \\
\hline Tasa de desempleo varones & & & & & $\begin{array}{c}21.0^{* *} \\
(2.47)\end{array}$ & $\begin{array}{c}16.3^{* *} \\
(2.32)\end{array}$ & $\begin{array}{c}18.1^{* *} \\
(2.18)\end{array}$ & $\begin{array}{c}13.5^{* *} \\
(2.23)\end{array}$ \\
\hline Controles adicionales & No & $\mathrm{Si}$ & No & $\mathrm{Si}$ & No & $\mathrm{Si}$ & No & $\mathrm{Si}$ \\
\hline Observaciones & 2,736 & 2,537 & 2,511 & 2,321 & 2,669 & 2,476 & 2,445 & 2,261 \\
\hline R-cuadrado ajustado & 0.316 & 0.377 & 0.331 & 0.397 & 0.323 & 0.378 & 0.337 & 0.397 \\
\hline
\end{tabular}

Notas: Estimaciones con efectos fijos (por país, grupo de edad y nivel educativo). Panel no balanceado de 18 países. Participación laboral como porcentaje de adultos (mujeres o varones) entre 25-54 años. Estadísticos t robustos entre paréntesis. ${ }^{*}$ significativo al $10 \%$; ** significativo al $5 \%$; ** significativo al $1 \%$.

Como resultado general se observa que la significatividad y el signo de los coeficientes se mantienen para todas las especificaciones, aunque la magnitud de los mismos se ve reducida al incorporar variables al modelo (el efecto de un aumento del $10 \%$ en el componente cíclico del producto pasa de una reducción de aproximadamente 1.47 pp. a una de 0.48 pp. aproximadamente).

Al incluir la tasa de desempleo masculina, el coeficiente asociado al componente cíclico del producto ve reducida su magnitud, aunque sigue siendo significativa. Además,

\footnotetext{
${ }^{17}$ Es importante notar que incluir el salario de la mujer y una medida de la importancia del sector servicios contribuye a controlar factores relacionados a la demanda laboral que a su vez están correlacionados con el ciclo económico. De esta forma, se estará captando el hecho de que las recesiones o las expansiones de corto plazo del producto pueden generar cambios composicionales en la estructura productiva que afectan la PLF.

${ }^{18}$ Las correlaciones de cada uno de estos controles adicionales con la PLF, al ser estimadas mediante modelos de efectos fijos bivariados, tienen los signos esperados según la literatura empírica (ver Busso y Fonseca, 2015.
}

${ }^{19}$ Los Cuadros B9 y B10 (Apéndice B) muestran los resultados completos de los Cuadros 3 y 4. 
Cuadro 4. Modelos del ratio varones/mujeres de participación laboral (\%). Países de América Latina, panel de cohortes según educación y edad, 1987-2014. Individuos entre 25-54 años.

\begin{tabular}{|c|c|c|c|c|c|c|c|c|}
\hline & $(1)$ & $(2)$ & (3) & (4) & (5) & (6) & $(7)$ & (8) \\
\hline Componente cíclico & $\begin{array}{c}40.5^{* * *} \\
(6.17)\end{array}$ & $\begin{array}{c}35.4^{* * *} \\
(5.04)\end{array}$ & $\begin{array}{c}33.2^{* * *} \\
(4.84)\end{array}$ & $\begin{array}{c}21.9^{* * *} * \\
(3.03)\end{array}$ & $\begin{array}{c}25.1^{* * *} \\
(3.49)\end{array}$ & $\begin{array}{c}22.4^{* * *} \\
(3.35)\end{array}$ & $\begin{array}{c}19.7^{* * *} \\
(2.69)\end{array}$ & $\begin{array}{c}9.2 \\
(1.30)\end{array}$ \\
\hline Componente tendencial & $\begin{array}{c}-30.3^{* * *} \\
(-7.92)\end{array}$ & $\begin{array}{l}-10.1^{*} \\
(-1.79)\end{array}$ & $\begin{array}{c}-36.6^{* * *} \\
(-6.13)\end{array}$ & $\begin{array}{c}-20.2^{* * *} \\
(-3.94)\end{array}$ & $\begin{array}{c}-32.0 * * * \\
(-7.55)\end{array}$ & $\begin{array}{c}-12.5^{* *} \\
(-2.28)\end{array}$ & $\begin{array}{c}-38.2^{* * *} \\
(-5.96)\end{array}$ & $\begin{array}{c}-22.5^{* * *} \\
(-4.49)\end{array}$ \\
\hline Cobertura CCT & & & $\begin{array}{c}25.8^{* *} \\
(2.04)\end{array}$ & $\begin{array}{c}36.9 * * * \\
(3.69)\end{array}$ & & & $\begin{array}{l}26.6^{* *} \\
(2.05)\end{array}$ & $\begin{array}{c}38.4^{* * *} \\
(3.75)\end{array}$ \\
\hline Tasa de desempleo varones & & & & & $\begin{array}{c}-89.2^{* * *} \\
(-2.72)\end{array}$ & $\begin{array}{c}-70.4^{* * *} \\
(-3.16)\end{array}$ & $\begin{array}{c}-84.8^{* *} \\
(-2.59)\end{array}$ & $\begin{array}{c}-67.7^{* * *} \\
(-3.19)\end{array}$ \\
\hline Controles adicionales & No & $\mathrm{Si}$ & No & $\mathrm{Si}$ & No & $\mathrm{Si}$ & No & $\mathrm{Si}$ \\
\hline Observaciones & 2,736 & 2,537 & 2,511 & 2,321 & 2,669 & 2,476 & 2,445 & 2,261 \\
\hline R-cuadrado ajustado & 0.283 & 0.423 & 0.301 & 0.445 & 0.295 & 0.438 & 0.312 & 0.462 \\
\hline
\end{tabular}

Notas: Estimaciones con efectos fijos (por país, grupo de edad y nivel educativo). Panel no balanceado de 18 países. Participación laboral como porcentaje de adultos (mujeres o varones) entre 25-54 años. Estadísticos t robustos entre paréntesis. ${ }^{*}$ significativo al $10 \% ; *$ significativo al $5 \% ; * *$ significativo al $1 \%$.

la relación entre el desempleo de los varones y la PLF es positiva y significativa. Ambos resultados son coherentes con la presencia del efecto de trabajador adicional y es el que explicaría gran parte la asociación negativa entre la PLF y el ciclo.

En los modelos que incorporan la medida de programas de transferencias condicionados, se oberva que aumentos en la cobertura de los CCTs están asociados a reducciones de la PLF. Este resultado es consistente con la hipótesis de que mayores transferencias condicionadas pueden desacelerar la entrada de las mujeres al mercado laboral. La transferencia monetaria, al aumentar los ingresos de los hogares, puede reducir la necesidad de un trabajo remunerado adicional, normalmente proporcionado por cónyuges mujeres. Además de este efecto ingreso, las condicionalidades asociadas al subsidio también pueden desalentar la oferta laboral femenina. Dado que generalmente los CCTs son percibidos por mujeres, es probable que se asocie a las mismas la responsabilidad de cumplir con las condicionalidades. Este hecho podría ser un desincentivo a participar del mercado laboral para las mujeres, ya sea por posibilitar un aumento del tiempo que pasan fuera del mercado laboral, como así también, por un fortalecimiento de la división tradicional de las funciones dentro del hogar entre géneros.

Es interesante observar también los efectos sobre la brecha de participación laboral entre varones y mujeres (Cuadro 4). El resultado principal es que expansiones en el componente cíclico del PBI están asociados a una ampliación de la brecha de género. El coeficiente estimado es significativo para todas las especificaciones, salvo para la especificación (8), en donde el efecto es capturado principalmente por la variabilidad de la tasa de desempleo de los varones y la cobertura de CCTs. Aumentos del desempleo 
masculino están asociados fuertemente a reducciones de la brecha de participación laboral entre géneros, resultado consistente con la validez de la hipótesis de trabajador adicional. Por otro lado, aumentos en el tamaño de los programas de transferencia condicionadas amplian la brecha. Estos resultados pueden ser tomados como evidencia de los potenciales factores a través de los cuales el crecimiento de la participación laboral femenina se ha desacelerado. En este sentido, se destaca el ciclo económico vía el efecto de trabajador adicional y los mayores ingresos no laborales derivados de programas sociales.

\section{Efectos asimétricos del ciclo económico}

De acuerdo a la hipótesis del trabajo, el componente cíclico del PBI per cápita debería ser importante para explicar el gran aumento de la PLF durante la década del noventa, un período con gran inestabilidad económica, con crisis globales e idiosincráticas profundas. Por otro lado, también debería ser relevante en la década del 2000, especialmente a partir de mediados del período, que es cuando la PLF empezó a dar indicios de desaceleración.

En el Cuadro 5 se muestran los resultados de la estimación del modelo (4) dividiendo la muestra para dos diferentes períodos: 1987-2003 y 2004-2014. El ciclo económico parece estar fuerte y negativamente asociado a la PLF durante el primer período, resultado consistente con el aumento persistente de la actividad laboral femenina ante la inestabilidad económica presente en esta etapa. Por el contrario, los aumentos de corto plazo del producto parecen no estar asociados a la PLF durante el segundo período, ya que el coeficiente asociado al ciclo no es estadísticamente diferente de cero.

A pesar de esta evidencia, podría ocurrir que exista un efecto asimétrico del ciclo económico sobre la PLF, en el sentido de que la relación entre ambas variables sea diferente si se está por encima o por debajo de la tendencia del PBI per cápita. Para evaluar estos efectos asimétricos se reemplaza al componente cíclico por dos variables obtenidas al descomponer el ciclo en su fase negativa (por debajo de la tendencia) y positiva (por encima de la tendencia).

En el segundo panel del Cuadro 5 se observan los respectivos resultados, que muestran que durante el período 1987-2003 la parte del ciclo relevante para explicar la variabilidad

de la PLF es la fase negativa, mientras que la positiva no es estadísticamente significativa. Por otro lado, durante el período 2004-2014, al descomponer el ciclo se observa que es la fase positiva la que está negativamente relacionada con la PLF, mientras que la fase negativa no es relevante. Al realizar un test formal para verificar la diferencia entre los coeficientes estimados de la parte positiva y negativa del ciclo, se encuentra que ésta es estadísticamente significativa, excepto en la especificación que incorpora los controles adicionales. Estos resultados es consistente con la hipótesis de que la desaceleración de la actividad laboral femenina que se dio a partir de la década del 2000, se debe a 
expansiones de corto plazo del producto.

Cuadro 5. Modelos de participación laboral femenina (\%) para diferentes períodos. Países de América Latina, panel de cohortes según educación y edad, 1989-2014. Individuos entre 25-54 años.

\begin{tabular}{|c|c|c|c|c|}
\hline & \multicolumn{2}{|c|}{ Período 1987-2003 } & \multicolumn{2}{|c|}{ Período 2004-2014 } \\
\hline & (1) & $(2)$ & $(3)$ & $(4)$ \\
\hline Componente cíclico & $\begin{array}{c}-17.8^{* * *} \\
(-5.65)\end{array}$ & $\begin{array}{c}-17.4^{* * *} \\
(-5.04)\end{array}$ & $\begin{array}{c}-2.3 \\
(-0.77)\end{array}$ & $\begin{array}{c}-1.4 \\
(-0.51)\end{array}$ \\
\hline Componente tendencial & $\begin{array}{c}12.1^{* * *} \\
(8.86)\end{array}$ & $\begin{array}{c}8.4^{* * *} \\
(4.38)\end{array}$ & $\begin{array}{l}5.0 * * * \\
(5.54)\end{array}$ & $\begin{array}{c}0.0 \\
(0.03)\end{array}$ \\
\hline \multicolumn{5}{|c|}{ Descomposición del componente cíclico } \\
\hline & $(5)$ & (6) & $(7)$ & $(8)$ \\
\hline Comp. cíclico negativo & $\begin{array}{c}-25.7^{* * *} \\
(-5.88)\end{array}$ & $\begin{array}{c}-24.0 * * * \\
(-4.78)\end{array}$ & $\begin{array}{c}11.4 \\
(1.61)\end{array}$ & $\begin{array}{c}6.5 \\
(0.95)\end{array}$ \\
\hline Comp. cíclico positivo & $\begin{array}{c}-2.9 \\
(-0.38)\end{array}$ & $\begin{array}{c}-6.7 \\
(-0.90)\end{array}$ & $\begin{array}{c}-11.3^{* * *} \\
(-3.01)\end{array}$ & $\begin{array}{c}-6.7^{*} \\
(-1.67)\end{array}$ \\
\hline Componente tendencial & $\begin{array}{c}12.1^{* * *} \\
(8.88)\end{array}$ & $\begin{array}{l}7.6^{* * *} \\
(3.89)\end{array}$ & $\begin{array}{c}4.6^{* * *} \\
(4.87)\end{array}$ & $\begin{array}{c}-0.2 \\
(-0.14)\end{array}$ \\
\hline Test diferencia & 5.045 & 2.815 & 6.107 & 2.064 \\
\hline P-valor & 0.026 & 0.095 & 0.015 & 0.153 \\
\hline Controles adicionales & No & $\mathrm{Si}$ & No & $\mathrm{Si}$ \\
\hline Observaciones & 1,278 & 1,142 & 1,458 & 1,395 \\
\hline
\end{tabular}

Notas: Estimaciones con efectos fijos (por país, grupo de edad y nivel educativo). Panel no balanceado de 18 países. Participación laboral como porcentaje de mujeres entre 25-54 años. Estadísticos t robustos entre paréntesis. ${ }^{*}$ significativo al $10 \%$; ** significativo al $5 \%$; ** significativo al $1 \%$.

\section{Estimaciones con variables instrumentales}

Los modelos estimados hasta el momento presentan el problema de sesgo por endogeneidad, incluso luego de controlar por la heterogeneidad no observable entre países, grupos de nivel educativo y de edad, que no varían en el tiempo. Esta última estrategia no contribuye a resolver otras fuentes de endogeneidad, como errores de medición en las variables explicativas de interés, o la causalidad inversa entre PLF y ciclo económico.

Es interesante analizar cuál podría ser la dirección del sesgo. En primer lugar, la existencia de errores de medición en el componente cíclico del PBI per cápita generarían 
coeficientes estimados atenuados, siendo el sesgo más grande en la medida que la varianza del error sea más imporante. Además, el sesgo provocado por la relación recíproca entre el ciclo y la PLF también podría atenuar el coeficiente estimado por mínimos cuadrados ordinarios. Si se supone que la PLF afecta positivamente el crecimiento económico, especialmente las expansiones cíclicas de corto plazo del producto, entonces, si no se considera esta relación, el efecto negativo del ciclo sobre la PLF debería tender a cero Wooldridge, 2010.

Para resolver el problema de endogeneidad, se propone como estrategia de identificación la obtención de los estimadores de variables instrumentales a través del método de mínimos cuadrados en dos etapas (2SLS), para poder aislar el efecto del componente cíclico del PBI sobre la participación laboral femenina. Las variables a utilizar para instrumentar el componente cíclico y tendencial del producto son variables meteorológicas, como los niveles de temperatura anual o de precipitaciones anuales promedio 20 Para que estos instrumentos sean válidos deben cumplir con la denominada condición de relevancia (deben afectar al crecimiento económico) y con la restricción de exclusión (deben afectar a la PLF sólo a través del crecimiento económico).

Para evaluar la primera condición se estima la primera etapa, que es la siguiente: ${ }^{21}$

$$
\text { ciclo }_{c t}=\gamma+\delta Z_{c t}+\phi X_{c t}+\theta Q_{g c t}+\eta_{c}+\epsilon_{t}+\mu_{c t}
$$

en donde $Z_{c t}$ corresponde a los intrumentos adicionales, que son el componente cíclico y tendencial de la temperatura anual y precipitaciones anuales promedio. Este modelo es el mismo para el caso en donde, además del ciclo, se considera al componente tendencial como variable endógena. El Cuadro 6 muestra que los instrumentos correspondientes a la temperatura se encuentran negativamente asociados al ciclo económico, mientras que los de precipitaciones lo hacen de forma positiva, aunque los coeficientes son pequeños pero estadísticamente significativos ${ }^{22}$ La intuición detrás de estas relaciones, por un lado provienen del hecho de que mayores temperaturas perjudican tanto el nivel como el crecimiento del producto, ya que afectan negativamente al sector agrícola, importante en la mayoría de los países latinoamericanos, especialmente si están relacionados a épocas

\footnotetext{
${ }^{20}$ Las variables son las mismas que utilizan Burke et al. 2015.

${ }^{21}$ Las estimaciones de la primera etapa proveen información interesante adicional sobre los efectos del clima sobre el crecimiento del producto. Miguel et al. 2004, para explicar el conflicto civil, analiza un grupo de países africanos en el período 1981-1991, y muestra que el crecimiento anual del ingreso per cápita está positivamente relacionado con precipitaciones actuales y rezagadas, cuando no se controla por temperatura. Según Miguel y Satyanath 2011 esta relación se torna débil a partir del 2000 para el grupo de países que utiliza. El trabajo de Brückner y Ciccone 2011, cuyo objetivo es estudiar determinantes de los procesos de democratización, encuentran que shocks negativos en las precipitaciones disminuyen el ingreso en África Subsahariana. También, Burke y Leigh 2010 encuentran que la temperatura es un predictor más fuerte del ingreso en relación a las precipitaciones.

${ }^{22}$ Según los test $\mathrm{F}$ de significatividad conjunta de los parámetros asociados a los instrumentos adicionales sugeridos por Angrist y Pischke 2009, todos superan el umbral de 10.
} 
de sequía 23 Por el otro, las precipitaciones deberían afectar positivamente el producto, siendo más fuerte en economías que dependen del sector agrícola, que no tienen sistemas de riego extendidos y que se encuentran cerca del ecuador Miguel y Satyanath, 2011.

Respecto a la restricción de exclusión, el hecho de que ambos instrumentos sean considerados exógenos frente a diversas variables de interés, no garantiza que la influencia de estas variables sobre la actividad laboral femenina opere exclusivamente a través del ciclo del producto, pero es altamente probable que así suceda. Los instrumentos serán válidos en la medida que la temperatura o las precipitaciones no afecten directamente la PLF. Hay trabajos que encuentran una relación entre variables meteorológicas y oferta laboral, pero generalmente presentan evidencia micro usando un enfoque de horas de trabajo-ocio, o ven el efecto sobre la productividad laboral. Esto hace que si bien afecta la decisión en el margen interno (horas), es poco probable que afecte el margen externo. En los casos sobreidentificados, para los cuales se puede testear estadísticamente la validez de los instrumentos y/o la correcta especificación del modelo, los test de sobreidentificación son superados a los niveles tradicionales de significatividad (es decir, no se rechaza la hipótesis nula de instrumentos no correlacionados con el término de error).

Como se observa en el Cuadro 6, en todas las especificaciones, independientemente de si se considera el ciclo y la tendencia como variables endógenas, y de qué instrumentos se utilizan, el coeficiente estimado para el componente cíclico del producto sigue siendo negativo, pero es mayor que el que se obtuvo anteriormente (el efecto de una expansión de corto plazo del PBI del $10 \%$ genera una reducción de la participación laboral femenina entre 11 pp. y 5.7 pp.). Si los instrumentos son válidos, este resultado indicaría que las estimaciones anteriores tenían un sesgo de atenuación.

Esta estrategia se incluye en el trabajo como un ejercicio de robustez, sobre todo por la desconfianza en la validez de los instrumentos. Más allá de que estadísticamente los instrumentos no son débiles, los argumentos económicos sobre los cuales se basa esta relación no parecen del todo convincentes. Igualmente, si se considera que el sesgo por endogeneidad atenúa el efecto del ciclo, todos los resultados presentados en el trabajo estimarían un piso del efecto del ciclo económico sobre la PLF.

\footnotetext{
${ }^{23}$ Resultado consistente con los de la literatura empírica, como Burke et al. 2015, Dell et al. 2012 o Hsiang 2010, quienes incluso encuentran que la temperatura también afecta al sector industrial, sobre todo en economías pobres.
} 


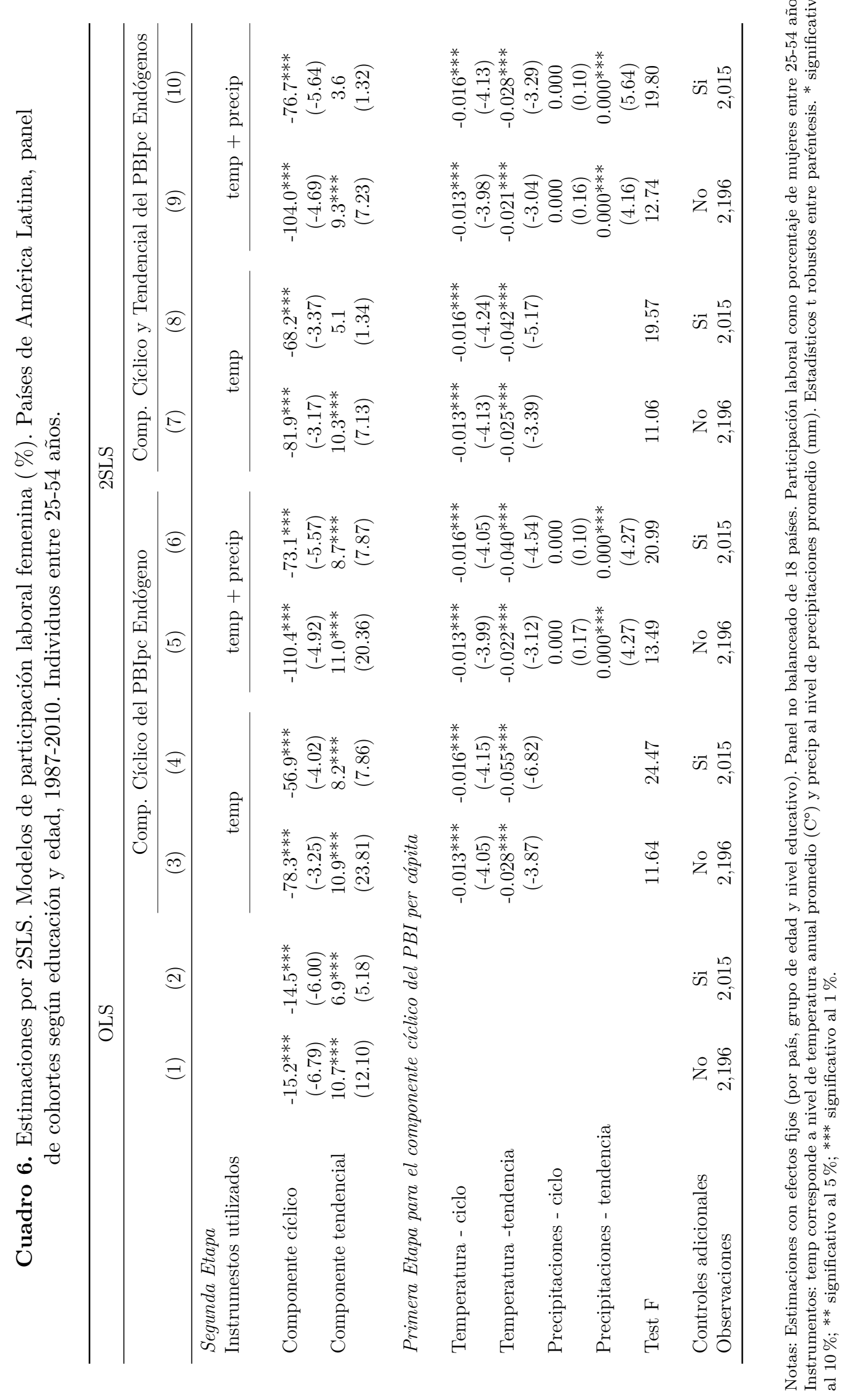




\section{Conclusiones}

El objetivo principal del trabajo es analizar el rol del crecimiento económico en la desaceleración de la PLF que sucede en la región a inicios de la década del dos mil. Para ello, se evalúa la relación entre el ciclo económico y la PLF mediante estimaciones de modelos econométricos con efectos fijos. En términos generales se encuentra que la participación laboral femenina está positivamente relacionada con el componente tendencial del PBI per cápita - efecto a largo plazo - y negativamente relacionado al componente cíclico — vinculado más a schoks de corto plazo.

$\mathrm{Al}$ analizar heterogeneidades se observa que el patrón contracíclico de la PLF es más fuerte para el grupo para el cual la desaceleración es más fuerte (mujeres más vulnerables, de menor educación, casadas, con hijos, en áreas rurales y en hogares de bajos ingresos). Este comportamiento puede ser explicado por el efecto de trabajador adicional a la inversa, al estar fuertemente asociado a los cambios en el desempleo masculino. Asimismo, se aporta evidencia de que la cobertura de programas de transferencias condicionadas es otro factor relevante asociado a la desaceleración de la actividad laboral femenina.

Asimismo, se encuentra que a partir de mediados de la década del 2000 el efecto negativo del ciclo del PBI se da principalmente por la parte del componente cíclico positiva, es decir, aquella que se encuentra por encima de la tendencia del PBI. Este resultado es coherente con que la desaceleración de la PLF, que ocurre en ese mismo período, se da mayormente por las expansiones del ciclo por encima de su tendencia.

$\mathrm{Al}$ explotar la variación exógena de variables meteorológicas sobre el ciclo del PBI, se encuentra que la relación negativa entre el ciclo y la PLF es generalmente mayor a la estimada anteriormente. Si los instrumentos son válidos, las estimaciones anteriores deberían subestimar el efecto al no tener en cuenta la relación simultánea entre ambas variables ni errores de medición. En cualquier caso, los modelos que no resuelven direcamente el problema de endogeneidad, estiman un piso de dicho efecto.

Las implicancias sobre el bienestar de la desaceleración de la PLF no son del todo claras. Esta transformación podría deberse al hecho de que ante un contexto económico más favorable, las mujeres ya no se ven forzadas a salir al mercado laboral y tomar trabajos precarios, de mala calidad, que no se ajusten a sus preferencias. En este sentido, la desaceleración podría ser el reflejo de una respuesta óptima de las mujeres que eligen destinar su tiempo a actividades fuera del mercado, como el cuidado de niños y la atención a adultos mayores. Sin embargo, como se sugiere en Gasparini y Marchionni 2015a, el hecho de permanecer fuera del mercado laboral durante algún tiempo podría implicar la pérdida de productividad, provocando una menor probabilidad de trabajar en el futuro, independientemente de las condiciones macroeconómicas. Además, podría significar un fortalecimiento de los roles tradicionales de género en el hogar, afectando negativamente las perspectivas de participación de las mujeres en el largo plazo. Esta 
visión más pesimista es particularmente relevante en el contexto actual, en donde algunas economías latinoamericanas, como Brasil y Argentina, padecen ciertos desequilibrios económicos que amenazan sus perspectivas de crecimiento. Futuras investigaciones son necesarias, sobre todo con datos no agregados, para poder tener conclusiones más precisas sobre los efectos en el comportamiento de las mujeres. 


\section{Referencias}

Angrist, J. D. y Pischke, J.-S. (2009). Mostly Harmless Econometrics: An Empiricist's Companion. Princeton University Press.

Ashenfelter, O. (1980). Unemployment as Disequilibrium in a Model of Aggregate Labor Supply. Econometrica, 48(3):547-64.

Attanasio, O., Levell, P., Low, H., y Sánchez-Marcos, V. (2015). Aggregating Elasticities: Intensive and Extensive Margins of Female Labour Supply. NBER Working Papers 21315, National Bureau of Economic Research, Inc.

Basu, K., Genicot, G., y Stiglitz, J. E. (2000). Unemployment and Wage Rigidity When Labor Supply Is a Household Decision. Working Papers 00-10, Cornell University, Center for Analytic Economics.

Beccaria, L., Maurizio, R., y Vázquez, G. (2015). El estancamiento de la tasa de participación económica femenina en Argentina en los 2000s. Mimeo.

Bhalotra, S. R. y Umana-Aponte, M. (2010). The Dynamics of Women's Labour Supply in Developing Countries. IZA Discussion Papers 4879, Institute for the Study of Labor (IZA).

Borjas, G. (2005). Labor economics, volumen 1. McGraw-Hill New York.

Brückner, M. y Ciccone, A. (2011). Rain and the Democratic Window of Opportunity. Econometrica, 79(3):923-947.

Burke, M., Hsiang, S. M., y Miguel, E. (2015). Global non-linear effect of temperature on economic production. Nature, 527(7577):235-239.

Burke, P. J. y Leigh, A. (2010). Do Output Contractions Trigger Democratic Change? American Economic Journal: Macroeconomics, 2(4):124-57.

Busso, M. y Fonseca, D. R. (2015). Determinants of female labor force participation. En Gasparini, L. y Marchionni, M., editores, Bridging gender gaps? The rise and deceleration of female labor force participation in Latin America, volumen 1, capítulo 6, pp. 199-260. Center for Distributive, Labor and Social Studies, 1st edición.

Cerrutti, M. (2000). Economic reform, structural adjustment and female labor force participation in Buenos Aires, Argentina. World Development, 28(5):879-891.

Chioda, L. (2011). Work and Family: Latin American 8 Caribbean Women in Search of a New Balance. World Bank. 
Cox Edwards, A. y Roberts, J. (1994). The effects of structural adjustment on women in Latin America. En Horton, S., R., K., y M., D., editores, Labor Markets in an Era of Adjustment, volumen 1. Washington, DC: World Bank, 1st edición.

Darby, J., Hart, R., y Vecchi, M. (1998). Labour force participation and the business cycle: A comparative analysis of europe, japan and the united states. Working papers, Business School - Economics, University of Glasgow.

Dell, M., Jones, B. F., y Olken, B. A. (2012). Temperature Shocks and Economic Growth: Evidence from the Last Half Century. American Economic Journal: Macroeconomics, $4(3): 66-95$.

Fernandes, R. y Felicio, F. (2005). The Entry of the Wife into the Labor Force in Response to the Husband's Unemployment: A Study of the Added Worker Effect in Brazilian Metropolitan Areas. Technical report, Economic Development and Cultural Change.

Garganta, S., Gasparini, L., y Marchionni, M. (2015). Social Policy and Female Labor Force Participation: the case of AUH in Argentina. L reunión anual, Anales de la Asociación Argentina de Economía Política.

Gasparini, L. y Gluzmann, P. (2015). Female participation and the economic cycle. En Gasparini, L. y Marchionni, M., editores, Bridging gender gaps? The rise and deceleration of female labor force participation in Latin America, volumen 1, capítulo 5, pp. 199-260. Center for Distributive, Labor and Social Studies, 1st edición.

Gasparini, L. y Marchionni, M. (2015a). Bridging gender gaps? The rise and deceleration of female labor force participation in Latin America. Center for Distributive, Labor and Social Studies, La Plata, Buenos Aires, Argentina, 1 edición.

Gasparini, L. y Marchionni, M. (2015b). Implications of female labor force participation. En Gasparini, L. y Marchionni, M., editores, Bridging gender gaps? The rise and deceleration of female labor force participation in Latin America, volumen 1, capítulo 6, pp. 199-260. Center for Distributive, Labor and Social Studies, 1st edición.

Gasparini, L., Marchionni, M., Badaracco, N., y Serrano, J. (2015). Characterizing female participation changes. En Gasparini, L. y Marchionni, M., editores, Bridging gender gaps? The rise and deceleration of female labor force participation in Latin America, volumen 1, capítulo 4, pp. 199-260. Center for Distributive, Labor and Social Studies, 1st edición.

Gruber, J. y Cullen, J. B. (1996). Spousal Labor Supply as Insurance: Does Unemployment Insurance Crowd Out the Added Worker Effect? NBER Working Papers 5608, National Bureau of Economic Research, Inc. 
Heckman, J. J. y Macurdy, T. E. (1980). A Life Cycle Model of Female Labour Supply. Review of Economic Studies, 47(1):47-74.

Hodrick, R. y Prescott, E. (1997). Postwar u.s. business cycles: An empirical investigation. Journal of Money, Credit and Banking, 29(1):1-16.

Hsiang, S. M. (2010). Temperatures and Cyclones Strongly Associated with Economic Production in the Caribbean and Central America. Proceedings of the National Academy of Sciences, 107(35):15367-15372.

Lee, G. H. y Parasnis, J. (2014). Discouraged workers in developed countries and added workers in developing countries? Unemployment rate and labour force participation. Economic Modelling, 41(C):90-98.

Lundberg, S. (1985). The Added Worker Effect. Journal of Labor Economics, 3(1):11-37.

Martinoty, L. (2015). Intra-Household Coping Mechanisms in Hard Times: the Added Worker Effect in the 2001 Argentine Economic Crisis. Working paper, Working paper GATE 2015-05.

McKenzie, D. J. (2003a). Aggregate shocks and urban labor market responses: evidence from Argentina's financial crisis. Centre for Research on Economic Development and Policy Reform Working Paper 176, Standford university.

McKenzie, D. J. (2003b). How do Households Cope with Aggregate Shocks? Evidence from the Mexican Peso Crisis. World Development, 31(7):1179-1199.

Miguel, E. y Satyanath, S. (2011). Re-examining economic shocks and civil conflict. American Economic Journal: Applied Economics, 3(4):228-232.

Miguel, E., Satyanath, S., y Sergenti, E. (2004). Economic Shocks and Civil Conflict: An Instrumental Variables Approach. Journal of Political Economy, 112(4):725-753.

Parker, S. y Skoufias, E. (2004). The added worker effect over the business cycle: evidence from urban Mexico. Technical report, Applied Economics Letters.

Paz, J. A. (2009). El Efecto del Trabajador Adicional: Evidencia para Argentina (2003-2007). Cuadernos de economía, 46:225 - 241.

Peña, X., Bernal, R., y Amador, D. (2013). The rise in female participation in Colombia: Fertility, marital status or education? Ensayos sobre política económica, 31(71):54-63.

SEDLAC (2014). Socioeconomic Database for Latin America and the Caribbean. Technical report, CEDLAS-World Bank. 
Stampini, M. y Tornarolli, L. (2012). The Growth of Conditional Cash Transfers in Latin America and the Caribbean: Did They Go Too Far? IZA Policy Papers 49, Institute for the Study of Labor (IZA).

Stephens, M. (2002). Worker Displacement and the Added Worker Effect. Journal of Labor Economics, 20(3):504-537.

Tachibanaki, T. y Sakurai, K. (1991). Labour supply and unemployment in Japan. European Economic Review, 35(8):1575-1587.

Wooldridge, J. M. (2010). Econometric Analysis of Cross Section and Panel Data, volumen 1 de MIT Press Books. The MIT Press.

World Bank (2012). The effects of women's economic power in Latin America and the Caribbean. Technical Report 21315, Poverty and Labor Brief - LAC region.

Woytinsky, W. S. (1940). Additional workers and the volume of unemployment in the depression. Pamphlet series 1, Washington: Social Science Research Council, Committee on Social Security. 


\section{Apéndice A}

Figura A1. Participación laboral femenina y masculina. Países de América Latina 1989-2014.

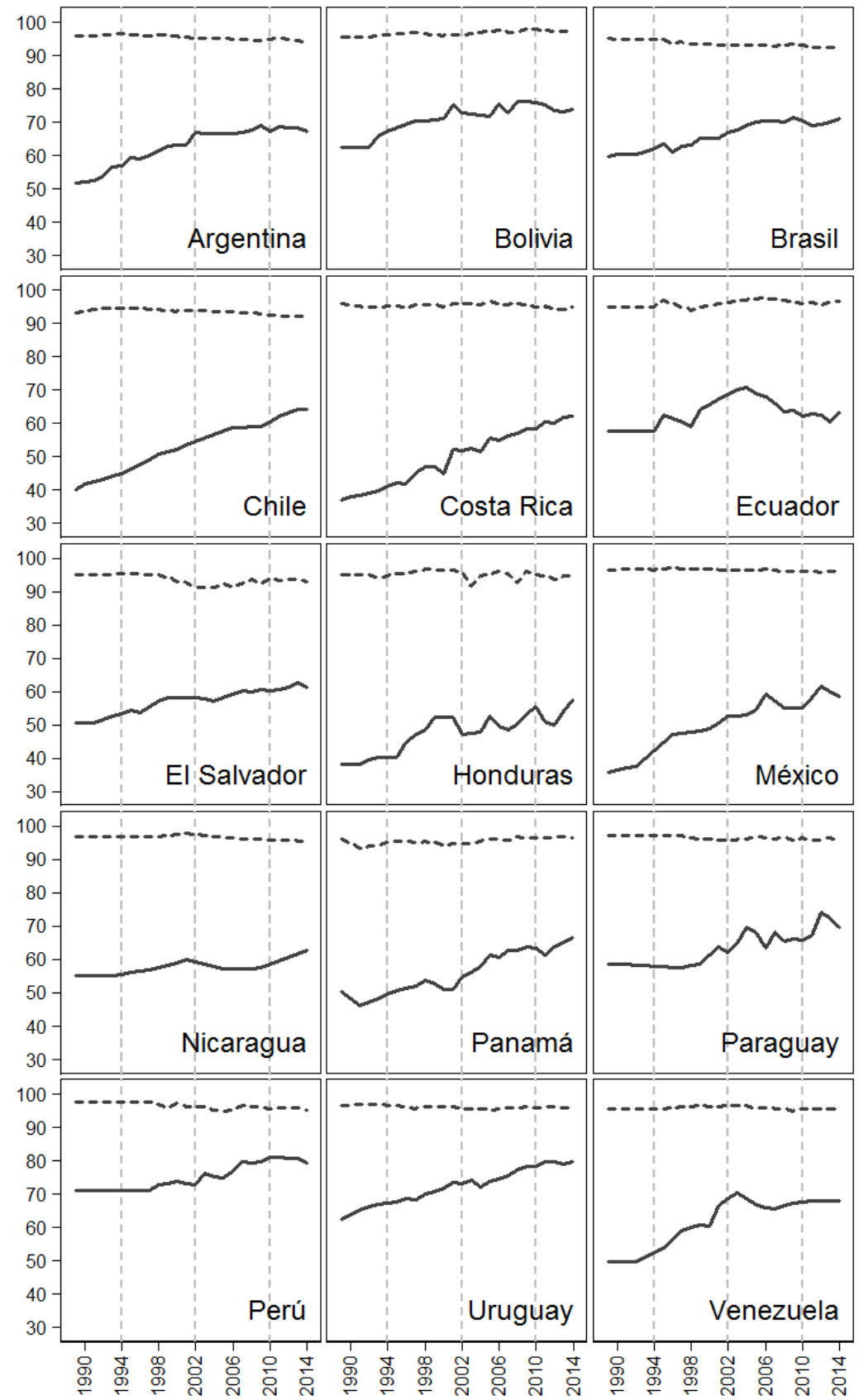

Mujeres

Varones

Fuente: Elaboración propia en base a microdatos provenientes de encuestas de hogares. Nota: Adultos (mujeres y varones) entre 25 y 54 años. 
Figura A2. PBI per cápita. Países de América Latina 1989-2014.

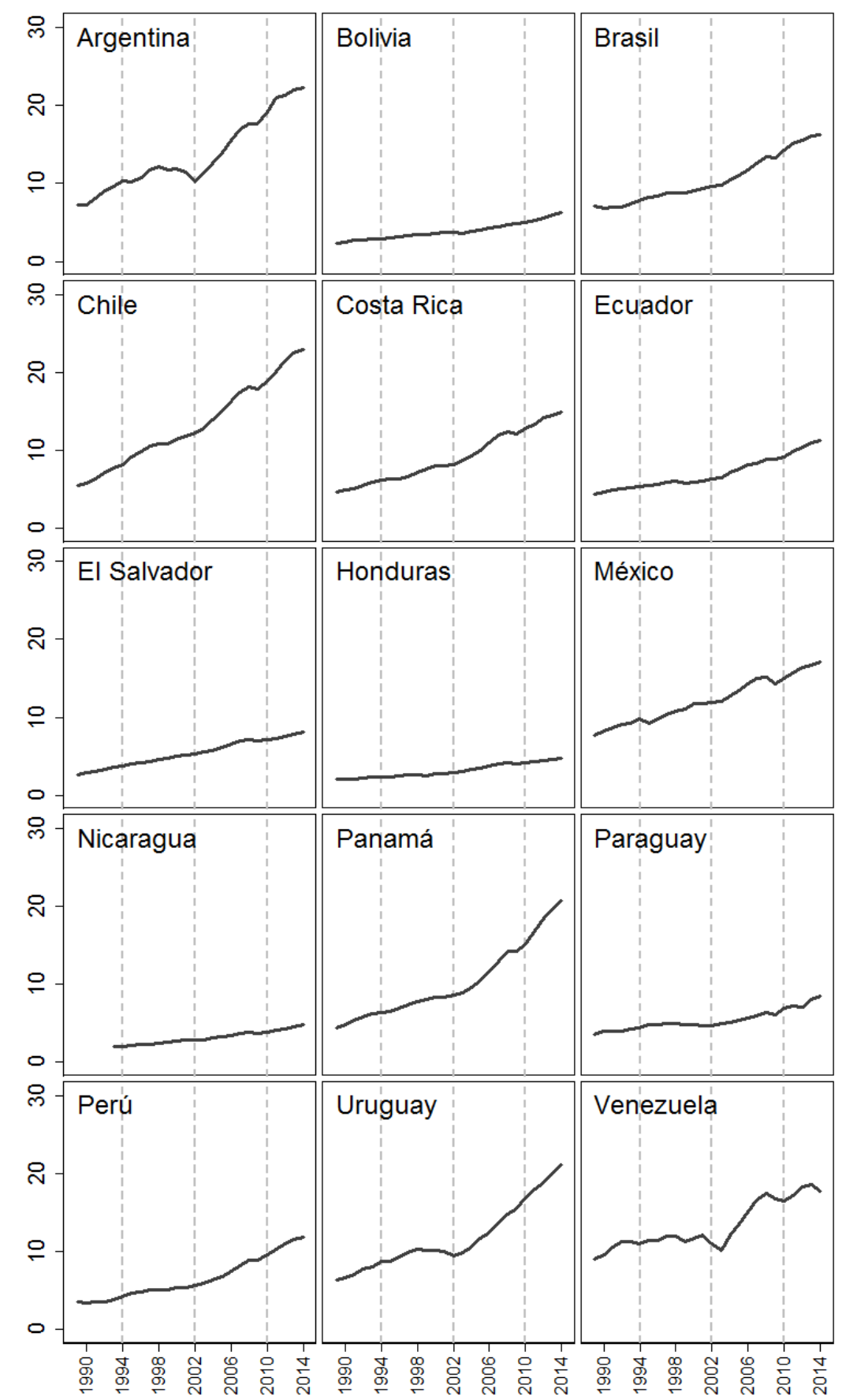

Fuente: Elaboración propia en base a datos de WEO 2016 (Fondo Monetario Internacional).

Nota: PBI per cápita en miles de U\$D ajustados por paridad de poder adquisitivo. 
Figura A3. Participación laboral femenina. América Latina. 19892014

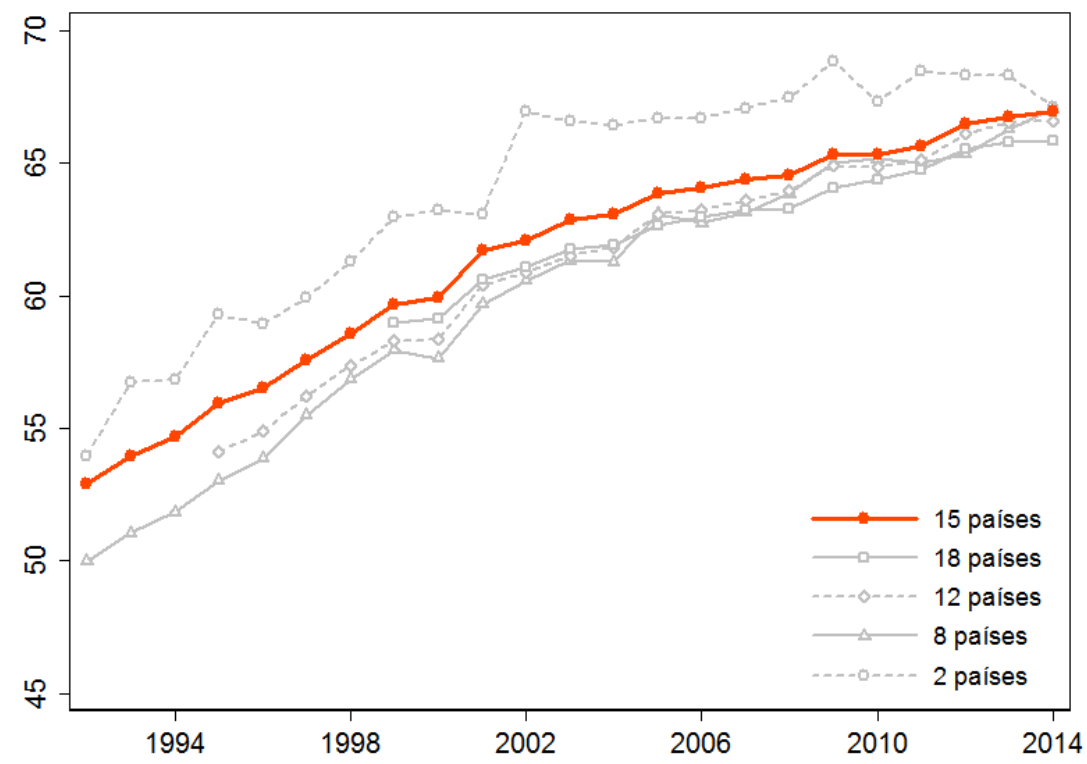

Fuente: Elaboración propia en base a encuestas de hogares.

Nota: Mujeres de 25-54 años de edad. Promedios no ponderados. 


\section{Apéndice B}

Cuadro B1. Encuestas de hogares utilizadas.

\begin{tabular}{|c|c|c|c|}
\hline País & Nombre de la encuesta & Sigla & Encuestas utilizadas \\
\hline Argentina & $\begin{array}{l}\text { Encuesta Permanente de Hogares Puntual } \\
\text { Encuesta Permanente de Hogares Contínua }\end{array}$ & $\begin{array}{l}\mathrm{EPH} \\
\mathrm{EPH}-\mathrm{C}\end{array}$ & $\begin{array}{l}1992-2003 \\
2003-2014\end{array}$ \\
\hline Bolivia & $\begin{array}{l}\text { Encuesta Integrada de Hogares } \\
\text { Encuesta Nacional de Empleo } \\
\text { Encuesta Contínua de Hogares } \\
\text { Encuesta de Hogares }\end{array}$ & $\begin{array}{l}\text { EIH } \\
\text { ENE } \\
\text { ECH } \\
\text { EH }\end{array}$ & $\begin{array}{l}1992,1993 \\
1997 \\
1999,2000 \\
2001,2002,2005,2007-2009 \\
2011-2013\end{array}$ \\
\hline Brazil & Pesquisa Nacional por Amostra de Domicilios & PNAD & $\begin{array}{l}\text { 1987-1993, 1995-1999, } \\
\text { 2001-2009, 2011-2014 }\end{array}$ \\
\hline Chile & Encuesta de Caracterización Socioeconómica Nacional & CASEN & $\begin{array}{l}\text { 1987, 1990, 1992, 1994, 1996, 1998, } \\
2000,2003,2006,2009,2011, \\
2013\end{array}$ \\
\hline Colombia & $\begin{array}{l}\text { Encuesta Continua de Hogares } \\
\text { Gran Encuesta Integrada de Hogares }\end{array}$ & $\begin{array}{l}\text { ECH } \\
\text { GEIH }\end{array}$ & $\begin{array}{l}2001-2005 \\
2008-2014\end{array}$ \\
\hline Costa Rica & $\begin{array}{l}\text { Encuesta de Hogares de Propósitos Múltiples } \\
\text { Encuesta nacional de hogares }\end{array}$ & $\begin{array}{l}\text { EHPM } \\
\text { ENAHO }\end{array}$ & $\begin{array}{l}1989-2009 \\
2010,2012-2014\end{array}$ \\
\hline Dominican R. & Encuesta Nacional de Fuerza de Trabajo & ENFT & $2000-2014$ \\
\hline Ecuador & $\begin{array}{l}\text { Encuesta de Condiciones de Vida } \\
\text { Encuesta Nacional de Empleo, Desempleo y Subempleo }\end{array}$ & $\begin{array}{l}\text { ECV } \\
\text { ENEMDU }\end{array}$ & $\begin{array}{l}\text { 1994, 1995, 1998, 1999, } \\
\text { 2003-2014 }\end{array}$ \\
\hline El Salvador & Encuesta de Hogares de Propósitos Múltiples & EHPM & $1991,1995,1996,1998-2014$ \\
\hline Guatemala & Encuesta Nacional sobre Condiciones de Vida & ENCOVI & $2000,2006,2011$ \\
\hline Honduras & Encuesta Permanente de Hogares de Propósitos Múltiples & EPHPM & 1991-1999, 2001-2013 \\
\hline Mexico & Encuesta Nacional de Ingresos y Gastos de los Hogares & ENIGH & $\begin{array}{l}\text { 1989, 1992, 1994, 1996, 1998, } \\
\text { 2000, 2002, 2004-2006, 2008, } \\
2010,2012,2014\end{array}$ \\
\hline Nicaragua & Encuesta Nacional de Hogares sobre Medición de Nivel de Vida & EMNV & $1993,1998,2001,2005,2009$ \\
\hline Panama & $\begin{array}{l}\text { Encuesta de Hogares, Mano de Obra } \\
\text { Encuesta de Hogares }\end{array}$ & $\begin{array}{l}\mathrm{EMO} \\
\mathrm{EH}\end{array}$ & $\begin{array}{l}1989,1991 \\
1995,1997-2012 \\
\end{array}$ \\
\hline Paraguay & $\begin{array}{l}\text { Encuesta de Hogares (Mano de Obra) } \\
\text { Encuesta Integrada de Hogares } \\
\text { Encuesta Permanente de Hogares }\end{array}$ & $\begin{array}{l}\mathrm{EH} \\
\mathrm{EIH} \\
\mathrm{EPH}\end{array}$ & $\begin{array}{l}1990 \\
1997,2001 \\
1999,2002-2014\end{array}$ \\
\hline Peru & Encuesta Nacional de Hogares & ENAHO & $1997-2014$ \\
\hline Uruguay & Encuesta Continua de Hogares & $\mathrm{ECH}$ & $\begin{array}{l}\text { 1989, 1992, 1995-1998, } \\
2000-2014\end{array}$ \\
\hline Venezuela & Encuesta de Hogares Por Muestreo & EHM & $1989,1992,1995,1997-2011$ \\
\hline
\end{tabular}


Cuadro B2. Descripción y fuente de variables utilizadas

\begin{tabular}{|c|c|c|}
\hline Variable & Definición & Fuente \\
\hline Log PBI per cápita & $\begin{array}{l}\text { Producto bruto interno per cápita } \\
\text { ajustado a paridad de poder } \\
\text { adquisitivo (PPP) }\end{array}$ & $\begin{array}{l}\text { International Monetary Fund, } \\
\text { World Economic Outlook Database, } \\
\text { April } 2016\end{array}$ \\
\hline Cobertura CCT & $\begin{array}{l}\text { Ratio de beneficiarios de programas de } \\
\text { transferencias de ingresos condicionadas } \\
\text { sobre la población total. }\end{array}$ & $\begin{array}{l}\text { Beneficiarios de CCT: elaboración } \\
\text { propia en base a datos de CEPAL. } \\
\text { Población total: WDI, Banco Mundial }\end{array}$ \\
\hline Tasa de desempleo varones & $\begin{array}{l}\text { Ratio de varones desocupados sobre } \\
\text { varones en edad de trabajar }\end{array}$ & Encuestas de hogares \\
\hline Años de educación & Años de educación promedio (en logs) & Encuestas de hogares \\
\hline Número de hijos & Número de hijos promedio (en logs) & Encuestas de hogares \\
\hline Casadas & Porcentaje de mujeres casadas & Encuestas de hogares \\
\hline Adultos mayores a cargo & $\begin{array}{l}\text { Porcentaje de mujeres que tienen a } \\
\text { su cargo a algún adulto mayor de } \\
70 \text { años de edad }\end{array}$ & Encuestas de hogares \\
\hline Edad hijos & Edad promedio de hijos en el hogar & Encuestas de hogares \\
\hline Ratio salarios (varon/mujer) & $\begin{array}{l}\text { Ratio de ingreso laboral horario promedio } \\
\text { de la ocupación principal entre varones y } \\
\text { mujeres, ajustados a PPP } 2005\end{array}$ & Encuestas de hogares \\
\hline Salarios mujeres & $\begin{array}{l}\text { Ingreso laboral horario promedio de la } \\
\text { ocupación principal de las mujeres, } \\
\text { ajustados a PPP } 2005\end{array}$ & Encuestas de hogares \\
\hline Valor agregado S. Servicios & $\begin{array}{l}\text { Valor agregado del sector servicios } \\
(\% \text { de } \mathrm{PBI})\end{array}$ & WDI, Banco Mundial \\
\hline Población rural & Población rural ( \% de la población total) & WDI, Banco Mundial \\
\hline Temperatura & Temperatura anual promedio $\left(\mathrm{C}^{\circ}\right)$ & Burke et al. 2015 \\
\hline Precipitaciones & Precipitaciones anuales promedio $(\mathrm{mm})$ & Burke et al. 2015 \\
\hline
\end{tabular}


Cuadro B3. Modelos de empleo (\%), desempleo (\%) y salarios.

Países de América Latina, panel 1987-2014. Individuos entre 25-54 años.

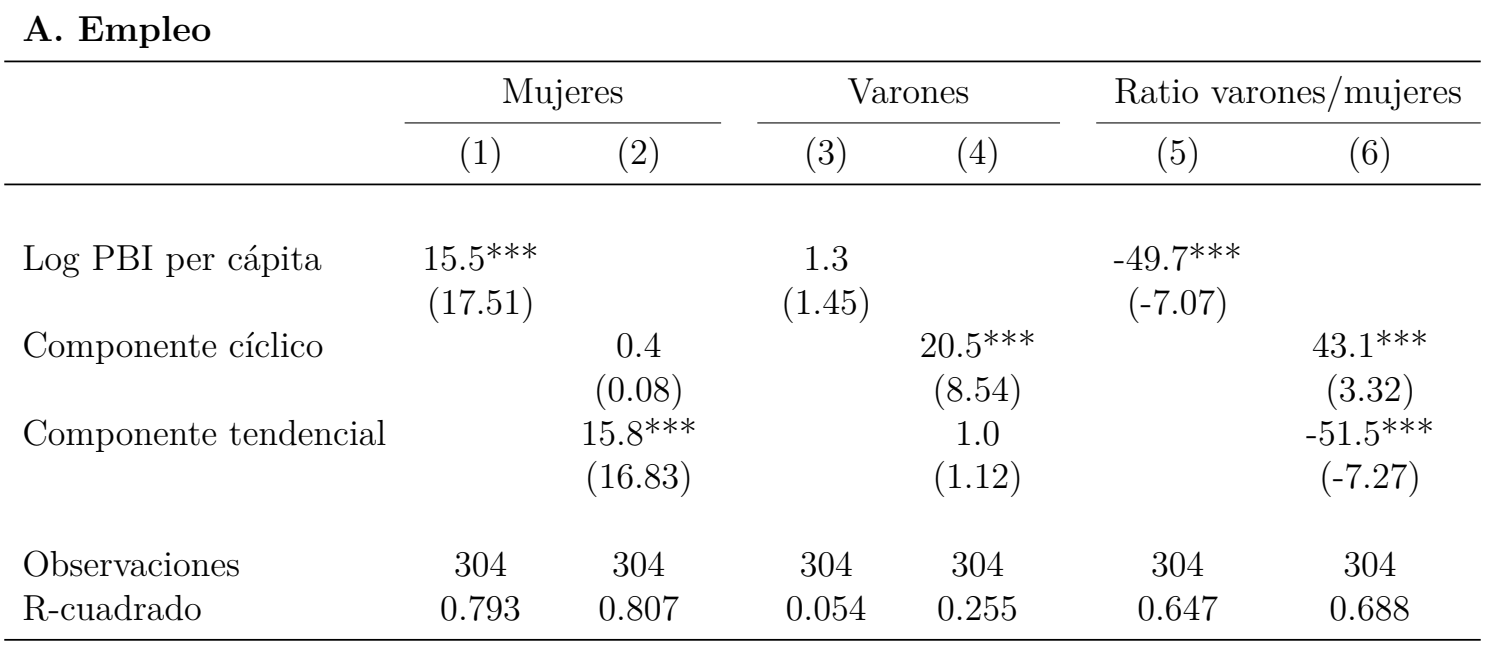

\section{B. Desocupación}

\begin{tabular}{|c|c|c|c|c|c|}
\hline \multicolumn{2}{|c|}{ Mujeres } & \multicolumn{2}{|c|}{ Varones } & \multicolumn{2}{|c|}{ Ratio varones/mujeres } \\
\hline$(1)$ & $(2)$ & $(3)$ & $(4)$ & (5) & $(6)$ \\
\hline
\end{tabular}

\begin{tabular}{|c|c|c|c|c|c|c|}
\hline Log PBI per cápita & $\begin{array}{l}-3.3^{* *} \\
(-2.21)\end{array}$ & & $\begin{array}{l}-2.2^{* *} \\
(-2.83)\end{array}$ & & $\begin{array}{l}-10.0 \\
(-1.47)\end{array}$ & \\
\hline Componente cíclico & & $\begin{array}{c}-25.0^{* * *} \\
(-5.81)\end{array}$ & & $\begin{array}{c}-18.8^{* * *} \\
(-10.97)\end{array}$ & & $\begin{array}{c}-10.6 \\
(-0.38)\end{array}$ \\
\hline Componente tendencial & & $\begin{array}{c}-2.9^{*} \\
(-1.94)\end{array}$ & & $\begin{array}{l}-1.9^{* *} \\
(-2.56)\end{array}$ & & $\begin{array}{l}-10.0 \\
(-1.40)\end{array}$ \\
\hline Observaciones & 303 & 303 & 303 & 303 & 303 & 303 \\
\hline R-cuadrado & 0.117 & 0.208 & 0.171 & 0.341 & 0.026 & 0.026 \\
\hline
\end{tabular}

\section{Salario horario}

\begin{tabular}{|c|c|c|c|c|c|c|}
\hline & \multicolumn{2}{|c|}{ Mujeres } & \multicolumn{2}{|c|}{ Varones } & \multicolumn{2}{|c|}{ Ratio varones/mujeres } \\
\hline & (1) & (2) & $(3)$ & $(4)$ & $(5)$ & $(6)$ \\
\hline Log PBI per cápita & $\begin{array}{c}0.2^{* * *} \\
(3.09)\end{array}$ & & $\begin{array}{l}0.2^{* *} \\
(2.46)\end{array}$ & & $\begin{array}{l}-5.1^{*} \\
(-1.96)\end{array}$ & \\
\hline Componente cíclico & & $\begin{array}{l}1.2^{* * *} \\
(4.24)\end{array}$ & & $\begin{array}{l}1.5^{* * *} \\
(6.29)\end{array}$ & & $\begin{array}{c}32.4^{* * *} \\
(3.13)\end{array}$ \\
\hline Componente tendencial & & $\begin{array}{l}0.2^{* *} \\
(2.73)\end{array}$ & & $\begin{array}{c}0.2^{*} \\
(2.05)\end{array}$ & & $\begin{array}{l}-5.8^{* *} \\
(-2.12)\end{array}$ \\
\hline Observaciones & 300 & 300 & 300 & 300 & 300 & 300 \\
\hline R-cuadrado & 0.209 & 0.269 & 0.135 & 0.253 & 0.044 & 0.089 \\
\hline
\end{tabular}

Notas: Estimaciones con efectos fijos (por país). Panel no balanceado de 18 países. Empleo como porcentaje de adultos (mujeres o varones) entre 25-54 años. Desocupación como porcentaje de la población económicamente activa (mujeres o varones) entre 25-54 años. Estadísticos t robustos entre paréntesis. * significativo al $10 \%$; ** significativo al $5 \%$; *** significativo al $1 \%$. 
Cuadro B4. Modelos de participación laboral ( \%) por número de hijos. Países de América Latina, panel 1987-2014. Individuos entre 25-54 años.

\begin{tabular}{|c|c|c|c|c|c|c|}
\hline & \multicolumn{2}{|c|}{ Sin hijos $<18$ años } & \multicolumn{2}{|c|}{ Con hijos de 0-5 años } & \multicolumn{2}{|c|}{ Con hijos de 6-17 años } \\
\hline & (1) & $(2)$ & (3) & (4) & (5) & $(6)$ \\
\hline Log PBI per cápita & $\begin{array}{c}15.6^{* * *} \\
(9.70)\end{array}$ & & $\begin{array}{c}14.4^{* * *} \\
(8.56)\end{array}$ & & $\begin{array}{l}15.4^{* * *} \\
(13.18)\end{array}$ & \\
\hline Componente cíclico & & $\begin{array}{l}-12.0^{*} \\
(-1.93)\end{array}$ & & $\begin{array}{c}-22.8^{* * *} \\
(-3.55)\end{array}$ & & $\begin{array}{c}-17.5^{* * *} \\
(-3.09)\end{array}$ \\
\hline Componente tendencial & & $\begin{array}{c}16.2^{* * * *} \\
(9.56)\end{array}$ & & $\begin{array}{c}15.0^{* * *} \\
(8.87)\end{array}$ & & $\begin{array}{c}16.1^{* * *} \\
(13.67)\end{array}$ \\
\hline Observaciones & 304 & 304 & 303 & 303 & 304 & 304 \\
\hline R-cuadrado & 0.650 & 0.687 & 0.583 & 0.654 & 0.661 & 0.716 \\
\hline
\end{tabular}

\section{B. Varones}

$\frac{\text { Sin hijos }<18 \text { años }}{(1)} \frac{\text { Con hijos de } 0-5 \text { años }}{(3)} \frac{\text { Con hijos de 6-17 años }}{(4)} \quad \frac{(5)}{(4)}$

$\begin{array}{lllllll}(1) & (2) & (3) & (4)\end{array}$

\begin{tabular}{|c|c|c|c|c|c|c|}
\hline Log PBI per cápita & $\begin{array}{c}1.0 \\
(1.69)\end{array}$ & & $\begin{array}{c}-0.0 \\
(-0.13)\end{array}$ & & $\begin{array}{l}0.9^{* *} \\
(2.85)\end{array}$ & \\
\hline Componente cíclico & & $\begin{array}{c}2.3 \\
(1.12)\end{array}$ & & $\begin{array}{c}1.2 \\
(1.40)\end{array}$ & & $\begin{array}{c}1.3 \\
(1.41)\end{array}$ \\
\hline Componente tendencial & & $\begin{array}{c}0.9 \\
(1.58)\end{array}$ & & $\begin{array}{c}-0.0 \\
(-0.22)\end{array}$ & & $\begin{array}{l}0.9^{* *} \\
(2.74)\end{array}$ \\
\hline Observaciones & 304 & 304 & 303 & 303 & 304 & 304 \\
\hline R-cuadrado & 0.050 & 0.052 & 0.000 & 0.007 & 0.116 & 0.116 \\
\hline
\end{tabular}

\section{Ratio varones/mujeres}

\begin{tabular}{|c|c|c|c|c|c|c|}
\hline & \multicolumn{2}{|c|}{ Sin hijos $<18$ años } & \multicolumn{2}{|c|}{ Con hijos de 0-5 años } & \multicolumn{2}{|c|}{ Con hijos de 6-17 años } \\
\hline & (1) & $(2)$ & $(3)$ & (4) & $(5)$ & (6) \\
\hline Log PBI per cápita & $\begin{array}{c}-45.7^{* * *} \\
(-5.75)\end{array}$ & & $\begin{array}{c}-72.9^{* * *} \\
(-4.84)\end{array}$ & & $\begin{array}{c}-50.3^{* * *} \\
(-6.28)\end{array}$ & \\
\hline Componente cíclico & & $\begin{array}{l}34.2^{*} \\
(2.07)\end{array}$ & & $\begin{array}{c}94.2^{* * *} \\
(3.68)\end{array}$ & & $\begin{array}{c}48.0^{* *} \\
(2.87)\end{array}$ \\
\hline Componente tendencial & & $\begin{array}{c}-47.3^{* * *} \\
(-5.82)\end{array}$ & & $\begin{array}{c}-75.6^{* * *} \\
(-4.99)\end{array}$ & & $\begin{array}{c}-52.3^{* * *} \\
(-6.48)\end{array}$ \\
\hline Observaciones & 304 & 304 & 303 & 303 & 304 & 304 \\
\hline R-cuadrado & 0.576 & 0.608 & 0.527 & 0.578 & 0.569 & 0.608 \\
\hline
\end{tabular}

Notas: Estimaciones con efectos fijos (por país). Panel no balanceado de 17 países. Participación laboral como porcentaje de mujeres entre 25-54 años. Estadísticos t robustos entre paréntesis. * significativo al 10\%; ** significativo al $5 \%$; *** significativo al $1 \%$. 
Cuadro B5. Modelos de participación laboral (\%) por quintiles de ingreso per cápita familiar. Países de América Latina, panel 1987-2014. Individuos entre 25-54 años.

\begin{tabular}{|c|c|c|c|c|}
\hline & \multicolumn{2}{|c|}{ Quintil 1} & \multicolumn{2}{|c|}{ Quintil 5} \\
\hline & $(1)$ & $(2)$ & (3) & (4) \\
\hline Log PBI per cápita & $\begin{array}{c}11.6^{* * *} \\
(4.45)\end{array}$ & & $\begin{array}{c}14.6^{* * *} \\
(9.85)\end{array}$ & \\
\hline Componente cíclico & & $\begin{array}{c}-35.9^{* * *} \\
(-3.93)\end{array}$ & & $\begin{array}{c}-6.1 \\
(-1.51)\end{array}$ \\
\hline Componente tendencial & & $\begin{array}{c}12.6^{* * *} \\
(4.64)\end{array}$ & & $\begin{array}{l}15.0^{* * *} \\
(10.23)\end{array}$ \\
\hline Observaciones & 304 & 304 & 304 & 304 \\
\hline R-cuadrado & 0.308 & 0.401 & 0.732 & 0.759 \\
\hline
\end{tabular}

B. Varones

Quintil 1

\begin{tabular}{|c|c|c|c|c|}
\hline & $(1)$ & $(2)$ & $(3)$ & $(4)$ \\
\hline Log PBI per cápita & $\begin{array}{l}-2.5^{* *} \\
(-2.60)\end{array}$ & & $\begin{array}{c}0.0 \\
(0.09)\end{array}$ & \\
\hline Componente cíclico & & $\begin{array}{c}-3.2 \\
(-1.28)\end{array}$ & & $\begin{array}{c}3.3^{*} \\
(1.99)\end{array}$ \\
\hline Componente tendencial & & $\begin{array}{l}-2.5^{* *} \\
(-2.51)\end{array}$ & & $\begin{array}{c}-0.0 \\
(-0.05)\end{array}$ \\
\hline Observaciones & 304 & 304 & 304 & 304 \\
\hline R-cuadrado & 0.118 & 0.118 & 0.000 & 0.022 \\
\hline \multicolumn{5}{|c|}{ C. Ratio varones/mujeres } \\
\hline & \multicolumn{2}{|c|}{ Quintil 1} & \multicolumn{2}{|c|}{ Quintil 5} \\
\hline & (1) & $(2)$ & $(3)$ & (4) \\
\hline Log PBI per cápita & $\begin{array}{c}-117.9^{* * *} \\
(-3.83)\end{array}$ & & $\begin{array}{c}-26.0^{* * *} \\
(-7.15)\end{array}$ & \\
\hline Componente cíclico & & $\begin{array}{c}131.2^{* *} \\
(2.20)\end{array}$ & & $\begin{array}{l}15.7^{*} \\
(2.09)\end{array}$ \\
\hline Componente tendencial & & $\begin{array}{c}-122.9 * * * \\
(-3.93)\end{array}$ & & $\begin{array}{c}-26.8^{* * *} \\
(-7.48)\end{array}$ \\
\hline Observaciones & 304 & 304 & 304 & 304 \\
\hline R-cuadrado & 0.399 & 0.432 & 0.661 & 0.691 \\
\hline
\end{tabular}

Quintil 5

Notas: Estimaciones con efectos fijos (por país). Panel no balanceado de 18 países. Participación laboral como porcentaje de adultos (mujeres o varones) entre 25-54 años. Quintiles de la distribución del ingreso per capita familiar: quintil 1= grupo conformado por el $20 \%$ de menores ingresos de la población, quintil $5=$ grupo conformado por el $20 \%$ de mayores ingresos de la población. Estadísticos t robustos entre paréntesis. * significativo al $10 \%$; ** significativo al $5 \%$; *** significativo al $1 \%$. 
Cuadro B6. Modelos de participación laboral femenina (\%) por estado civil. Países de América Latina, panel 1987-2014. Mujeres entre 25-54 años.

\begin{tabular}{|c|c|c|c|c|c|c|}
\hline & \multicolumn{2}{|c|}{ Casadas } & \multicolumn{2}{|c|}{ Solteras } & \multicolumn{2}{|c|}{ Divorciadas/viudas } \\
\hline & (1) & $(2)$ & $(3)$ & $(4)$ & $(5)$ & (6) \\
\hline Log PBI per cápita & $\begin{array}{c}15.2^{* * *} \\
(10.39)\end{array}$ & & $\begin{array}{c}6.2^{* * *} \\
(3.71)\end{array}$ & & $\begin{array}{c}7.6^{* * *} \\
(4.84)\end{array}$ & \\
\hline Componente cíclico & & $\begin{array}{c}-18.1^{* * *} \\
(-3.04)\end{array}$ & & $\begin{array}{c}-3.4 \\
(-0.49)\end{array}$ & & $\begin{array}{l}-9.2^{*} \\
(-1.77)\end{array}$ \\
\hline Componente tendencial & & $\begin{array}{c}15.8^{* * *} \\
(10.53)\end{array}$ & & $\begin{array}{l}6.4^{* * *} \\
(3.67)\end{array}$ & & $\begin{array}{l}8.0^{* * *} \\
(5.02)\end{array}$ \\
\hline Constante & $\begin{array}{c}-81.9 * * * \\
(-6.24)\end{array}$ & $\begin{array}{c}-87.9 * * * \\
(-6.50)\end{array}$ & $\begin{array}{c}19.9 \\
(1.32)\end{array}$ & $\begin{array}{c}18.0 \\
(1.15)\end{array}$ & $\begin{array}{c}8.2 \\
(0.58)\end{array}$ & $\begin{array}{c}5.0 \\
(0.35)\end{array}$ \\
\hline Observaciones & 291 & 291 & 273 & 273 & 273 & 273 \\
\hline R-cuadrado & 0.666 & 0.727 & 0.261 & 0.273 & 0.373 & 0.410 \\
\hline
\end{tabular}

Notas: Estimaciones con efectos fijos (por país). Panel no balanceado de 18 países. Participación laboral femenina como porcentaje de mujeres entre $25-54$ años. Estadísticos t robustos entre paréntesis. * significativo al $10 \%$; $* *$ significativo al $5 \%$; *** significativo al $1 \%$.

Cuadro B7. Modelos de participación laboral femenina ( \%) por área de residencia. Países de América Latina, panel 1987-2014. Mujeres entre 25-54 años.

\begin{tabular}{lccccc}
\hline & \multicolumn{2}{c}{ Área rural } & & \multicolumn{2}{c}{ Área urbana } \\
\cline { 2 - 3 } \cline { 5 - 6 } & $(1)$ & $(2)$ & & $(3)$ & $(4)$ \\
\hline \multirow{2}{*}{ Log PBI per cápita } & $13.8^{* * *}$ & & & $12.3^{* * *}$ \\
& $(6.27)$ & & & $(7.80)$ \\
Componente cíclico & & $-23.8^{* *}$ & & & $-17.1^{* * *}$ \\
& & $(-2.71)$ & & $(-3.48)$ \\
Componente tendencial & & $14.5^{* * *}$ & & $12.9^{* * *}$ \\
Constante & & $(6.23)$ & & $(8.53)$ \\
& $-71.4^{* * *}$ & $-76.9^{* * *}$ & & $-45.6^{* * *}$ & $-50.8^{* * *}$ \\
Observaciones & $(-3.62)$ & $(-3.71)$ & & $(-3.22)$ & $(-3.74)$ \\
R-cuadrado & & & & 304 \\
\hline
\end{tabular}

Notas: Estimaciones con efectos fijos (por país). Panel no balanceado de 18 países. Participación laboral femenina como porcentaje de mujeres entre $25-54$ años. Estadísticos $t$ robustos entre paréntesis. ${ }^{*}$ significativo al $10 \%$; ** significativo al $5 \%$; ** significativo al $1 \%$. 
Cuadro B8. Modelos de participación laboral ( \%) por tipo de familia. Países de América Latina, panel 1987-2014. Individuos entre 25-54 años.

\section{A. Mujeres}

\begin{tabular}{|c|c|c|c|c|c|c|}
\hline & \multicolumn{2}{|c|}{ Nuclear con dos padres } & \multicolumn{2}{|c|}{ Nuclear monoparental } & \multicolumn{2}{|c|}{ Unipersonal } \\
\hline & (1) & $(2)$ & (3) & (4) & $(5)$ & (6) \\
\hline Log PBI per cápita & $\begin{array}{c}14.7^{* * *} \\
(10.58)\end{array}$ & & $\begin{array}{l}7.5^{* * * *} \\
(6.88)\end{array}$ & & $\begin{array}{c}8.4^{* * * *} \\
(3.59)\end{array}$ & \\
\hline Componente cíclico & & $\begin{array}{c}-18.9^{* * *} \\
(-3.66)\end{array}$ & & $\begin{array}{c}-8.1 \\
(-1.56)\end{array}$ & & $\begin{array}{c}-1.7 \\
(-0.23)\end{array}$ \\
\hline Componente tendencial & & $\begin{array}{c}15.3^{* * *} \\
(10.91)\end{array}$ & & $\begin{array}{l}7.8^{* * *} \\
(6.97)\end{array}$ & & $\begin{array}{c}8.6^{\text {*** }} \\
(3.54)\end{array}$ \\
\hline Observaciones & 304 & 304 & 304 & 304 & 304 & 304 \\
\hline R-cuadrado & 0.652 & 0.714 & 0.448 & 0.483 & 0.203 & 0.208 \\
\hline
\end{tabular}

B. Varones

\begin{tabular}{|c|c|c|c|c|c|c|}
\hline & \multicolumn{2}{|c|}{ Nuclear } & \multicolumn{2}{|c|}{ Sin cónyuge } & \multicolumn{2}{|c|}{ Unipersonal } \\
\hline & (1) & $(2)$ & (3) & (4) & $(5)$ & (6) \\
\hline Log PBI per cápita & $\begin{array}{c}-0.4 \\
(-1.00)\end{array}$ & & $\begin{array}{c}-1.2 \\
(-1.42)\end{array}$ & & $\begin{array}{c}0.8 \\
(1.35)\end{array}$ & \\
\hline Componente cíclico & & $\begin{array}{c}1.3 \\
(1.06)\end{array}$ & & $\begin{array}{c}1.8 \\
(0.68)\end{array}$ & & $\begin{array}{l}8.7^{* *} \\
(2.67)\end{array}$ \\
\hline Componente tendencial & & $\begin{array}{c}-0.4 \\
(-1.09)\end{array}$ & & $\begin{array}{c}-1.3 \\
(-1.45)\end{array}$ & & $\begin{array}{c}0.6 \\
(1.06)\end{array}$ \\
\hline Observaciones & 304 & 304 & 304 & 304 & 304 & 304 \\
\hline R-cuadrado & 0.021 & 0.029 & 0.041 & 0.046 & 0.015 & 0.045 \\
\hline
\end{tabular}

C. Ratio varones/mujeres

\begin{tabular}{|c|c|c|c|c|c|c|}
\hline & \multicolumn{2}{|c|}{ Nuclear } & \multicolumn{2}{|c|}{ Sin cónyuge } & \multicolumn{2}{|c|}{ Unipersonal } \\
\hline & (1) & (2) & $(3)$ & (4) & $(5)$ & (6) \\
\hline Log PBI per cápita & $\begin{array}{c}-60.0 * * * \\
(-5.44)\end{array}$ & & $\begin{array}{c}-15.0 * * * \\
(-8.74)\end{array}$ & & $\begin{array}{c}-12.3^{* * *} \\
(-3.09)\end{array}$ & \\
\hline Componente cíclico & & $\begin{array}{c}65.2^{* * *} \\
(3.54)\end{array}$ & & $\begin{array}{l}16.1^{*} \\
(2.07)\end{array}$ & & $\begin{array}{c}15.4 \\
(1.65)\end{array}$ \\
\hline Componente tendencial & & $\begin{array}{c}-62.5 * * * \\
(-5.60)\end{array}$ & & $\begin{array}{c}-15.7^{* * *} \\
(-9.00)\end{array}$ & & $\begin{array}{c}-12.8^{* * *} \\
(-3.14)\end{array}$ \\
\hline Observaciones & 304 & 304 & 304 & 304 & 304 & 304 \\
\hline R-cuadrado & 0.557 & 0.601 & 0.532 & 0.573 & 0.175 & 0.191 \\
\hline
\end{tabular}

Notas: Estimaciones con efectos fijos (por país). Panel no balanceado de 18 países. Participación laboral como porcentaje de mujeres entre 25-54 años. Tipos de hogar: nuclear= hogar con un/a jefe/a de hogar y su cónyuge, con 2 o más miembros; sin cónyuge $=$ hogar con más de un miembro, con un/a jefe/a de hogar sin cónyuge; unipersonal $=$ hogar compuesto sólo por el/la jefe/a de hogar. Estadísticos t robustos entre paréntesis. ${ }^{*}$ significativo al $10 \% ;{ }^{* *}$ significativo al $5 \%$;** significativo al $1 \%$. 
Cuadro B9. Modelos de participación laboral femenina (\%). Países de América Latina, panel de cohortes según educación y edad, 1987-2014. Individuos entre 25-54 años.

\begin{tabular}{|c|c|c|c|c|c|c|c|c|}
\hline & $(1)$ & $(2)$ & $(3)$ & (4) & $(5)$ & $(6)$ & $(7)$ & (8) \\
\hline Componente cíclico & $\begin{array}{c}-14.7^{* * * *} \\
(-6.64)\end{array}$ & $\begin{array}{c}-13.8^{* * *} \\
(-5.79)\end{array}$ & $\begin{array}{c}-11.3^{* * *} \\
(-5.02)\end{array}$ & $\begin{array}{c}-8.5^{* * *} \\
(-3.52)\end{array}$ & $\begin{array}{c}-10.6^{* * *} \\
(-4.39)\end{array}$ & $\begin{array}{c}-9.9^{* * *} \\
(-4.12)\end{array}$ & $\begin{array}{c}-7.8^{* * *} \\
(-3.33)\end{array}$ & $\begin{array}{l}-4.8^{* *} \\
(-2.05)\end{array}$ \\
\hline Componente tendencial & $\begin{array}{c}9.3^{* * *} \\
(12.64)\end{array}$ & $\begin{array}{c}4.7^{* * *} \\
(4.36)\end{array}$ & $\begin{array}{c}10.3^{* * *} \\
(9.55)\end{array}$ & $\begin{array}{l}7.2^{* * *} \\
(6.74)\end{array}$ & $\begin{array}{c}9.2^{* * *} \\
(12.03)\end{array}$ & $\begin{array}{l}5.4^{* * *} \\
(4.98)\end{array}$ & $\begin{array}{c}10.0^{\text {*** }} \\
(9.20)\end{array}$ & $\begin{array}{l}7.6^{* * *} \\
(7.37)\end{array}$ \\
\hline Cobertura CCT & & & $\begin{array}{c}-3.3 \\
(-1.28)\end{array}$ & $\begin{array}{c}-8.0^{* * *} \\
(-4.14)\end{array}$ & & & $\begin{array}{c}-2.8 \\
(-1.13)\end{array}$ & $\begin{array}{c}-7.9^{* * *} \\
(-4.07)\end{array}$ \\
\hline Tasa de desempleo varones & & & & & $\begin{array}{l}21.0^{* *} \\
(2.47)\end{array}$ & $\begin{array}{l}16.3^{* *} \\
(2.32)\end{array}$ & $\begin{array}{l}18.1^{* *} \\
(2.18)\end{array}$ & $\begin{array}{l}13.5^{* *} \\
(2.23)\end{array}$ \\
\hline Años de educación & & $\begin{array}{c}14.1 * * * \\
(4.31)\end{array}$ & & $\begin{array}{c}14.3^{* * *} \\
(4.42)\end{array}$ & & $\begin{array}{c}15.5^{* * *} \\
(4.70)\end{array}$ & & $\begin{array}{c}15.7^{* * * *} \\
(4.80)\end{array}$ \\
\hline Número de hijos & & $\begin{array}{c}-1.8 \\
(-0.82)\end{array}$ & & $\begin{array}{c}-2.2 \\
(-0.99)\end{array}$ & & $\begin{array}{c}-0.3 \\
(-0.14)\end{array}$ & & $\begin{array}{c}-0.7 \\
(-0.32)\end{array}$ \\
\hline Casadas & & $\begin{array}{c}-14.1^{* * *} \\
(-4.78)\end{array}$ & & $\begin{array}{c}-13.7^{* * *} \\
(-4.62)\end{array}$ & & $\begin{array}{c}-13.4^{* * *} \\
(-4.21)\end{array}$ & & $\begin{array}{c}-12.7^{* * *} \\
(-4.03)\end{array}$ \\
\hline Adultos mayores a cargo & & $\begin{array}{c}-5.3 \\
(-1.00)\end{array}$ & & $\begin{array}{c}-6.8 \\
(-1.30)\end{array}$ & & $\begin{array}{c}-7.2 \\
(-1.42)\end{array}$ & & $\begin{array}{c}-8.7^{*} \\
(-1.77)\end{array}$ \\
\hline Edad hijos & & $\begin{array}{c}-0.1 \\
(-0.77)\end{array}$ & & $\begin{array}{c}-0.0 \\
(-0.26)\end{array}$ & & $\begin{array}{c}0.0 \\
(0.01)\end{array}$ & & $\begin{array}{c}0.1 \\
(0.63)\end{array}$ \\
\hline Ratio salarios (varon/mujer) & & $\begin{array}{c}0.3^{*} \\
(1.83)\end{array}$ & & $\begin{array}{c}0.2 \\
(1.26)\end{array}$ & & $\begin{array}{l}0.3^{* *} \\
(2.18)\end{array}$ & & $\begin{array}{c}0.2^{*} \\
(1.72)\end{array}$ \\
\hline Salarios mujeres & & $\begin{array}{l}0.6^{* * *} \\
(3.11)\end{array}$ & & $\begin{array}{c}0.6^{* * *} \\
(2.98)\end{array}$ & & $\begin{array}{l}0.4^{* *} \\
(2.26)\end{array}$ & & $\begin{array}{l}0.4^{* *} \\
(2.00)\end{array}$ \\
\hline Valor agregado S. Servicios & & $\begin{array}{l}-0.1^{*} \\
(-1.68)\end{array}$ & & $\begin{array}{c}-0.1^{*} \\
(-1.83)\end{array}$ & & $\begin{array}{c}-0.1 \\
(-1.59)\end{array}$ & & $\begin{array}{c}-0.1 \\
(-1.59)\end{array}$ \\
\hline Población rural & & $\begin{array}{l}-0.2^{*} \\
(-1.84)\end{array}$ & & $\begin{array}{c}-0.2 \\
(-1.50)\end{array}$ & & $\begin{array}{c}-0.2 \\
(-1.33)\end{array}$ & & $\begin{array}{c}-0.1 \\
(-0.98)\end{array}$ \\
\hline Constante & $\begin{array}{c}-13.5^{* *} \\
(-2.05)\end{array}$ & $\begin{array}{l}15.0 \\
(0.94)\end{array}$ & $\begin{array}{c}-22.3^{* *} \\
(-2.35)\end{array}$ & $\begin{array}{c}-9.0 \\
(-0.58)\end{array}$ & $\begin{array}{c}-14.1^{* *} \\
(-2.01)\end{array}$ & $\begin{array}{c}0.1 \\
(0.01)\end{array}$ & $\begin{array}{c}-21.1^{* *} \\
(-2.16)\end{array}$ & $\begin{array}{l}-22.8 \\
(-1.55)\end{array}$ \\
\hline Observaciones & 2,736 & 2,537 & 2,511 & 2,321 & 2,669 & 2,476 & 2,445 & 2,261 \\
\hline R-cuadrado & 0.316 & 0.377 & 0.331 & 0.397 & 0.323 & 0.378 & 0.337 & 0.397 \\
\hline
\end{tabular}

Notas: Estimaciones con efectos fijos (por país, grupo de edad y nivel educativo). Panel no balanceado de 18 países. Participación laboral femenina como porcentaje de mujeres entre 25-54 años. Estadísticos t robustos entre paréntesis. * significativo al $10 \%$; ** significativo al $5 \%$; *** significativo al $1 \%$. 
Cuadro B10. Modelos del ratio varones/mujeres de participación laboral (\%). Países de América Latina, panel de cohortes según educación y edad, 1987-2014. Individuos entre 25-54 años.

\begin{tabular}{|c|c|c|c|c|c|c|c|c|}
\hline & (1) & $(2)$ & $(3)$ & $(4)$ & $(5)$ & $(6)$ & $(7)$ & $(8)$ \\
\hline Componente cíclico & $\begin{array}{c}40.5^{* * *} \\
(6.17)\end{array}$ & $\begin{array}{c}35.4^{* * *} \\
(5.04)\end{array}$ & $\begin{array}{c}33.2^{* * *} \\
(4.84)\end{array}$ & $\begin{array}{c}21.9^{* * *} \\
(3.03)\end{array}$ & $\begin{array}{c}25.1^{* * *} \\
(3.49)\end{array}$ & $\begin{array}{c}22.4^{* * *} \\
(3.35)\end{array}$ & $\begin{array}{c}19.7^{* * *} \\
(2.69)\end{array}$ & $\begin{array}{c}9.2 \\
(1.30)\end{array}$ \\
\hline Componente tendencial & $\begin{array}{c}-30.3^{* * *} \\
(-7.92)\end{array}$ & $\begin{array}{l}-10.1^{*} \\
(-1.79)\end{array}$ & $\begin{array}{c}-36.6^{* * *} \\
(-6.13)\end{array}$ & $\begin{array}{c}-20.2^{* * *} * \\
(-3.94)\end{array}$ & $\begin{array}{c}-32.0 * * * \\
(-7.55)\end{array}$ & $\begin{array}{c}-12.5^{* *} \\
(-2.28)\end{array}$ & $\begin{array}{c}-38.2^{* * *} \\
(-5.96)\end{array}$ & $\begin{array}{c}-22.5^{* * *} \\
(-4.49)\end{array}$ \\
\hline Cobertura CCT & & & $\begin{array}{c}25.8^{* *} \\
(2.04)\end{array}$ & $\begin{array}{c}36.9^{\text {*** }} \\
(3.69)\end{array}$ & & & $\begin{array}{c}26.6^{* *} \\
(2.05)\end{array}$ & $\begin{array}{c}38.4^{\text {**** }} \\
(3.75)\end{array}$ \\
\hline Tasa de desempleo varones & & & & & $\begin{array}{c}-89.2^{* * *} \\
(-2.72)\end{array}$ & $\begin{array}{c}-70.4^{* * *} \\
(-3.16)\end{array}$ & $\begin{array}{c}-84.8^{* *} \\
(-2.59)\end{array}$ & $\begin{array}{c}-67.7^{* * *} \\
(-3.19)\end{array}$ \\
\hline Años de educación & & $\begin{array}{c}-88.6^{* * *} \\
(-4.02)\end{array}$ & & $\begin{array}{c}-90.7^{* * *} * \\
(-3.98)\end{array}$ & & $\begin{array}{c}-91.5^{* * *} \\
(-4.13)\end{array}$ & & $\begin{array}{c}-93.6^{* * *} \\
(-4.10)\end{array}$ \\
\hline Número de hijos & & $\begin{array}{l}-13.2^{*} \\
(-1.67)\end{array}$ & & $\begin{array}{l}-12.0^{*} \\
(-1.66)\end{array}$ & & $\begin{array}{c}-18.6^{* *} \\
(-2.21)\end{array}$ & & $\begin{array}{c}-17.2^{* *} \\
(-2.26)\end{array}$ \\
\hline Casadas & & $\begin{array}{c}37.6^{\text {*** }} \\
(4.33)\end{array}$ & & $\begin{array}{c}37.4^{* * *} \\
(4.14)\end{array}$ & & $\begin{array}{c}33.7^{* * *} \\
(3.54)\end{array}$ & & $\begin{array}{c}32.3^{\text {*** }} \\
(3.28)\end{array}$ \\
\hline Adultos mayores a cargo & & $\begin{array}{c}-0.8 \\
(-0.06)\end{array}$ & & $\begin{array}{c}0.9 \\
(0.06)\end{array}$ & & $\begin{array}{c}2.9 \\
(0.20)\end{array}$ & & $\begin{array}{c}4.4 \\
(0.30)\end{array}$ \\
\hline Edad hijos & & $\begin{array}{c}1.1^{*} \\
(1.68)\end{array}$ & & $\begin{array}{c}0.8 \\
(1.30)\end{array}$ & & $\begin{array}{c}0.9 \\
(1.35)\end{array}$ & & $\begin{array}{c}0.7 \\
(0.95)\end{array}$ \\
\hline Ratio salarios (varon/mujer) & & $\begin{array}{l}-2.3^{* *} \\
(-2.46)\end{array}$ & & $\begin{array}{l}-2.1^{* *} \\
(-2.00)\end{array}$ & & $\begin{array}{c}-2.5 * * * \\
(-2.63)\end{array}$ & & $\begin{array}{l}-2.2^{* *} \\
(-2.19)\end{array}$ \\
\hline Salarios mujeres & & $\begin{array}{c}-0.7 \\
(-1.29)\end{array}$ & & $\begin{array}{c}-0.4 \\
(-0.81)\end{array}$ & & $\begin{array}{c}-0.5 \\
(-1.03)\end{array}$ & & $\begin{array}{c}-0.2 \\
(-0.46)\end{array}$ \\
\hline Valor agregado S. Servicios & & $\begin{array}{c}-0.0 \\
(-0.20)\end{array}$ & & $\begin{array}{c}-0.0 \\
(-0.21)\end{array}$ & & $\begin{array}{c}0.0 \\
(0.09)\end{array}$ & & $\begin{array}{c}0.0 \\
(0.03)\end{array}$ \\
\hline Población rural & & $\begin{array}{c}1.2^{*} \\
(1.77)\end{array}$ & & $\begin{array}{c}1.0 \\
(1.55)\end{array}$ & & $\begin{array}{c}1.3^{*} \\
(1.77)\end{array}$ & & $\begin{array}{c}1.1 \\
(1.58)\end{array}$ \\
\hline Constante & $\begin{array}{c}418.5^{* * *} \\
(12.15)\end{array}$ & $\begin{array}{c}381.0 * * * \\
(4.56)\end{array}$ & $\begin{array}{c}471.9^{* * *} \\
(8.97)\end{array}$ & $\begin{array}{c}481.2^{* * * *} \\
(5.86)\end{array}$ & $\begin{array}{c}437.9^{* * *} \\
(11.22)\end{array}$ & $\begin{array}{c}416.3^{* * *} \\
(4.95)\end{array}$ & $\begin{array}{c}490.6^{* * *} \\
(8.55)\end{array}$ & $\begin{array}{c}516.1^{* * *} \\
(6.28)\end{array}$ \\
\hline Observaciones & 2,736 & 2,537 & 2,511 & 2,321 & 2,669 & 2,476 & 2,445 & 2,261 \\
\hline R-cuadrado & 0.283 & 0.423 & 0.301 & 0.445 & 0.295 & 0.438 & 0.312 & 0.462 \\
\hline
\end{tabular}

Notas: Estimaciones con efectos fijos (por país, grupo de edad y nivel educativo). Panel no balanceado de 18 países. Participación laboral como porcentaje de adultos (mujeres o varones) entre 25-54 años. Estadísticos t robustos entre paréntesis. ${ }^{*}$ significativo al $10 \%$; ** significativo al $5 \%$; ** significativo al $1 \%$. 